\title{
An Evaluation of the Tribological Behavior of Cutting Fluid Additives on Aluminum-Manganese Alloys
}

\author{
Junhui Ma *, Olufisayo A. Gali and Reza A. Riahi \\ Department of Mechanical, Automotive and Materials Engineering, University of Windsor, \\ Windsor, ON N9B 3P4, Canada; gali@uwindsor.ca (O.A.G.); ariahi@uwindsor.ca (R.A.R.) \\ * Correspondence: ma15i@uwindsor.ca
}

check for updates

Citation: Ma, J.; Gali, O.A.; Riahi, R.A. An Evaluation of the Tribological Behavior of Cutting Fluid Additives on Aluminum-Manganese Alloys. Lubricants 2021, 9, 84. https:// doi.org/10.3390/lubricants9080084

Received: 18 June 2021

Accepted: 13 August 2021

Published: 21 August 2021

Publisher's Note: MDPI stays neutral with regard to jurisdictional claims in published maps and institutional affiliations.

Copyright: (c) 2021 by the authors. Licensee MDPI, Basel, Switzerland. This article is an open access article distributed under the terms and conditions of the Creative Commons Attribution (CC BY) license (https:// creativecommons.org/licenses/by/ $4.0 /)$.

\begin{abstract}
The introduction of additives enhances the friction and wear reduction properties of cutting fluids (CFs) as well as aids in improving the surface quality of the machined parts. This study examines the tribological behavior of polymer-based and phosphorus-based additives introduced into cutting fluids for the machining of Al-Mn alloys. Ball-on-disc tests were used to evaluate the coefficient of friction (COF) and lubrication failure temperature to study the performance of the additives in the cutting fluids. Surface characterization was performed on the sliding tracks induced on the Al-Mn disc surfaces and used to propose the wear and friction reduction mechanisms. The polymer-based additive possessed a higher temperature at which lubrication failure occurred, displayed comparable COF at a lower temperature under certain conditions, and possessed a steadier tribological behavior. However, the phosphorus-based additive was observed to display lower COF and wear damage from $200^{\circ} \mathrm{C}$ till failure. The lower COF values for the phosphorus-based additive at $200^{\circ} \mathrm{C}$ corresponded with lower surface damage on the Al-Mn surface. The phosphorus-based additive's performance at $200{ }^{\circ} \mathrm{C}$ could be attributed to the forming of a phosphorus-rich boundary layer within the sliding wear track, resulting in less surface damage on the Al-Mn surface and lower material transfer to the counterface steel ball surface.
\end{abstract}

Keywords: cutting fluid additives; polymer-based additive; phosphorus-based additive; tribolayers; Al-Mn alloys; adhesion

\section{Introduction}

Aluminum alloys have been widely used in automobile and aerospace manufacturing industries due to their high specific strength, good thermal conductivity, and corrosion resistance. However, the low cutting efficiency and surface integrity of structural parts limit the processing of aluminum alloys [1]. Cutting fluids are widely used in the machining operations of aluminum alloys to improve the tribological interaction between the drill and the workpiece. Previous work has revealed that the application of the cutting fluids in the machining of aluminum alloys could improve the machining accuracy by reducing the surface roughness of the workpiece [2,3]. Cutting fluids could also offer protection to the machined surface against oxidation and corrosion as a function of the additives introduced into them [2]. During the machining procedure, the cutting fluids also assist in ejecting the debris and reducing the heat generated during machining, thus improving tool life $[4,5]$. Cutting fluids can be broken down into two major components, the base fluid, and additives. Generally, the base fluid is either oil or water-based, acting as lubricity and cooling agents to reduce friction and heat generation within the cutting zone [6,7]. However, water-based fluids not only offer good lubrication, but better cooling performance than oil-based fluids [8]. Still, additives are introduced into the cutting fluids to improve on the existing properties of the cutting fluid and obtain supplementary ones.

The type of lubricity additive introduced into the cutting fluid also plays a role in the cutting fluid performance. Typical cutting fluid additives include fatty acids, phosphorus compounds, esters, and polymers. The improved performance of cutting fluids due to the 
inclusion of additives has been reported in the literature. A reduction in surface roughness and tool wear was noted with an $8 \%$ concentration of extreme pressure (EP) additive included during the turning of AISI 3040L [9]. Another experimental study showed that the cutting fluid with EP additive displayed higher welding loads and smaller scars under similar tribological conditions [10]. Additives can form sacrificial films, which could be worn away during tribological contact. Thus, additive-fortified films could offer greater resistance and support the greater loads [11]. Prior work showed that the high molecular polymer additives could help to increase the average drop size of the cutting fluids, providing higher machining production [12]. Gao et al. have reported that reduced friction coefficient and improved tribological properties were obtained with the introduction of CNT nanoparticles in the grinding process on a carbon fiber-reinforced polymer (CFRP) workpiece [13]. Winkeljann et al. suggested the introduction of macromolecules in the solution was able to reduce the friction through physical entanglement, and the efficiency of the lubricant entanglement depends on the lubricant macromolecule weight [14]. Ballon-disc tests have generally been used to evaluate the tribological properties of cutting fluids [15,16]. Wang et al. [17], examining the tribological properties of BP-liquid paraffin lubricants for titanium-steel contacts with a ball-on-disc tribometer, revealed an improvement in the COF and wear rate in comparison to the base oil. Januszkiewicz et al.'s [3] investigation into the oil release mechanism of oil-in-water emulsions revealed that oil-inwater emulsions release the oil on the contact surfaces at high temperatures, leading to the reduction of friction. At a critical temperature, the failure of the emulsion to release oil to the contact surface resulted in the failure of the emulsion.

A previous study [18] explored the drilling performance of polymer-based and phosphorus-based additives in cutting fluids during drilling on a titanium alloy. The performances of the additives were attributed to the formation of carbon-rich tribolayers and phosphorus-rich tribolayers on the flank surfaces for the respective additives. The drilling performance of the additives was noted to depend on the drilling condition employed. The phosphorus-based additive displayed lower SCE values under low speed/high feed rate conditions, while as the spindle speed increased and feed rates reduced, the polymer-based additive displayed lower SCE values. The formation of the tribolayer was observed to be required for the preferred cutting fluid additive performance during drilling conditions. However, further investigation into the tribological behavior of the cutting fluid would grant greater insight into the factors influencing the formation and behavior of these tribolayers.

This study was performed to examine the tribological behavior of these polymerbased and phosphorus-based additives. This tribological examination of the cutting fluid additives was performed using a ball-on-disc tribometer in such a manner as to provide insight on the behavior of the cutting fluid additives on aluminum-manganese alloys during machining operations. Aluminum-manganese alloys were used here to confirm that the relationship between the additives' performance and the tribological conditions employed was not related solely to titanium alloys. The additives' performance was examined on the aluminum alloy through the evaluation of the coefficient of friction (COF) and the damage induced during sliding contact. The influence of the constantly increasing temperatures experienced during drilling on the additive performance was evaluated, and the failure temperature of the cutting fluid additives was determined. The focus of this study was to examine the behavior of the cutting fluid additive during the tribological interaction of the drill surface and the Al-Mn workpiece. Therefore, surface characterization of the Al-Mn disc, representing the workpiece, and the steel ball counterface, representing the drill surface, was carried out to investigate the friction-reduction mechanism of the two additives.

\section{Materials and Methods}

A tribometer with a ball-on-disc configuration previously described in [19] was employed to investigate the tribological behavior of the additive-infused cutting fluids. The 
tribometer setup, shown in Figure 1, was retrofitted so that the configuration of the ball and disc was in a vertical position. The configuration was selected to characterize the thermomechanical properties of the fluids in a more conventional manner. The cutting fluid was provided through a syringe which was placed right above the location the ball and the disc made contact. This configuration of the ball and disc eliminates the build-up of excess lubricant, which better simulates lubricant starvation which can be experienced at several regions on the drill bit surface during tribological contact. Temperatures were monitored with a thermocouple placed in contact with the Al-Mn disc about $0.5 \mathrm{~mm}$ below the surface of the disc, previously described in [20].

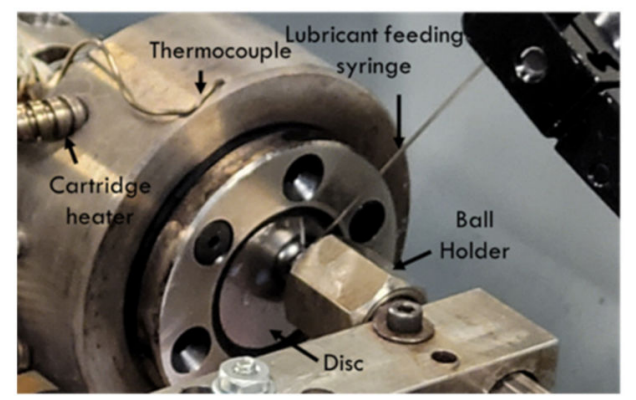

Figure 1. Experimental setup for the tribometer.

The experiments were carried out under two loads of $3 \mathrm{~N}$ and $5 \mathrm{~N}$, at a rotation speed of $0.1 \mathrm{~m} / \mathrm{s}$ and were repeated at least three times for each condition. The coefficient of friction (COF) and electrical resistance were recorded during each test. Aluminummanganese (Al-Mn) discs were machined to a $25 \mathrm{~mm}$ diameter and $12 \mathrm{~mm}$ thickness and polished to surface roughness $\left(\mathrm{R}_{\mathrm{a}}\right)$ of $0.99 \mu \mathrm{m}$. The Al-Mn alloy possessed a composition of $1.5 \mathrm{wt}$ \% Mn. AISI 52100 steel bearing balls of $10 \mathrm{~mm}$ diameter were used as the counterface and possessed a surface roughness $\left(R_{a}\right)$ of $0.15 \mu \mathrm{m}$, to evaluate the tribological behavior of cutting fluid additives [21,22]. The mechanical and thermophysical properties of the AISI 52100 steel and the Al-Mn alloy are displayed in Table 1. The balls and discs were ultrasonically cleaned in acetone before each test.

Table 1. Mechanical and thermophysical properties of the AISI 52100 steel ball and Al-Mn disc.

\begin{tabular}{cccccc}
\hline Properties & Yield Strength & Elastic Modulus & Hardness (Knoop) & $\begin{array}{c}\text { Thermal Expansion } \\
\text { Co-Efficient }\end{array}$ & $\begin{array}{c}\text { Thermal } \\
\text { Conductivity }\end{array}$ \\
\hline AISI 52100 & $2.03 \mathrm{GPa}$ & $200 \mathrm{GPa}$ & 732 & $11.9 \mu \mathrm{m} / \mathrm{m}^{\circ} \mathrm{C}$ & $46.6 \mathrm{~W} / \mathrm{mK}$ \\
\hline Al-Mn alloy & $125 \mathrm{MPa}$ & $75 \mathrm{GPa}$ & 70 & $23.2\left(10^{-6} /{ }^{\circ} \mathrm{C}\right)$ & $162 \mathrm{~W} / \mathrm{mK}$ \\
\hline
\end{tabular}

Tests were first performed to determine the lubrication failure temperature of the additives. The Al-Mn discs were heated from room temperature to $350{ }^{\circ} \mathrm{C}$ while in contact with the steel balls as the cutting fluids were dispensed. The electrical resistance between the Al-Mn disc and steel ball was monitored and combined with the COF to identify the failure in lubrication. Electrical resistance between the ball and disc was set to $100 \mathrm{ohms}$ approximately, and metal-to-metal contact is determined as a drop in electrical resistance, while the lubrication failure is determined as the drop in electrical resistance to zero and the sudden increase in COF [3]. Tests were then performed at constant temperatures of 100,200 , and $300{ }^{\circ} \mathrm{C}$ and allowed to run for a sliding distance of about $16.55 \mathrm{~m}$. The temperature at which lubrication failure occurred, critical temperature (Tc), and COF values were evaluated for each test, and the average values from these tests were recorded. The experimental conditions have been listed in Table 2. 
Table 2. Experimental conditions for the ball-on-disc test with Al-Mn samples against AISI 52100 steel ball at the rotation speed of $0.1 \mathrm{~m} / \mathrm{s}$.

\begin{tabular}{|c|c|c|}
\hline Parameters Products & Temperature & Load \\
\hline \multirow{4}{*}{ CF A } & $100^{\circ} \mathrm{C}$ & \multirow{3}{*}{$3 \mathrm{~N}, 5 \mathrm{~N}$} \\
\hline & $200^{\circ} \mathrm{C}$ & \\
\hline & $300{ }^{\circ} \mathrm{C}$ & \\
\hline & Lubrication Failure Temperature & $3 \mathrm{~N}$ \\
\hline \multirow{4}{*}{ CF B } & $100^{\circ} \mathrm{C}$ & \multirow{3}{*}{$3 \mathrm{~N}, 5 \mathrm{~N}$} \\
\hline & $200{ }^{\circ} \mathrm{C}$ & \\
\hline & $300^{\circ} \mathrm{C}$ & \\
\hline & Lubrication Failure Temperature & $3 \mathrm{~N}$ \\
\hline
\end{tabular}

Water-based cutting fluids with a $10 \%$ (wt. $/ \mathrm{wt}$.) concentration were introduced using a syringe at a feed rate of $3 \mathrm{~mL} / \mathrm{min}$. The tip of the syringe needle was held between the disc and ball to provide cutting fluid distribution. Two cutting fluids, referred to as cutting fluid A (CF A) and cutting fluid B (CF B), were examined. The additive in CF A was polymer-based, containing polyalkylene glycol (PAG), polymeric esters, and a low-level concentration of phosphorus concentration. The CF B additive includes a high concentration of phosphorus-based extreme pressure (EP) additive with a medium level of polymeric ester concentrations. Subsequently, the disc and ball specimen surfaces were then examined using an environmental scanning electron microscope (SEM) under a high vacuum to investigate the sliding tracks induced on the discs and the material transfer on the counter surface of the balls. Energy dispersive spectrometry (EDS) analysis was performed to confirm the material transfer to the steel counterface and the tribolayers induced on the Al-Mn surface.

\section{Experimental Results}

\subsection{Coefficient of Friction (COF) and Critical Temperature (Tc) Behavior of the Cutting Fluid Additives}

Initial tests with the cutting fluid additives were performed under the $3 \mathrm{~N}$ load. The experimental data obtained from the tests, the coefficient of friction (COF), temperature, and electrical resistance are plotted in the graphs presented in Figure 2 for both cutting fluids. The lubrication failure of the cutting fluids is illustrated in these graphs as the sudden rise in $\mathrm{COF}$, accompanied by a distinct drop in electrical resistance to zero. The drop in electrical resistance is an indication of metal-to-metal contact during the sliding period. An examination of Figure 2 reveals that the critical temperature (Tc) at which lubrication failure occurred for $\mathrm{CF} A\left(\sim 331.50^{\circ} \mathrm{C}\right)$ was higher than that of $\mathrm{CF} \mathrm{B}\left(\sim 283.0^{\circ} \mathrm{C}\right)$. The electrical resistance appeared to display a relatively stable performance for CF A (Figure 2a) until lubrication failure. However, a drop in electrical resistance was noted for CF B (Figure 2b) shortly after the start of the test, which recovered to become relatively stable at around $70{ }^{\circ} \mathrm{C}$ until lubrication failure. The COF behavior with the increase in temperature was relatively stable for CF A (Figure 2a) at $0.093 \pm 0.009$. However, a reduction in COF to $0.063 \pm 0.007$ was observed at around $290{ }^{\circ} \mathrm{C}$ for an average COF of $0.081 \pm 0.004$. The COF behavior of CF B was initially relatively stable at $0.043 \pm 0.100$; nevertheless, at around $160{ }^{\circ} \mathrm{C}$, a reduction of COF was observed, which stabilized at around $200{ }^{\circ} \mathrm{C}$ for a COF of $0.009 \pm 0.004$. The average COF for the CF B through the test duration until failure was $0.031 \pm 0.010$. 

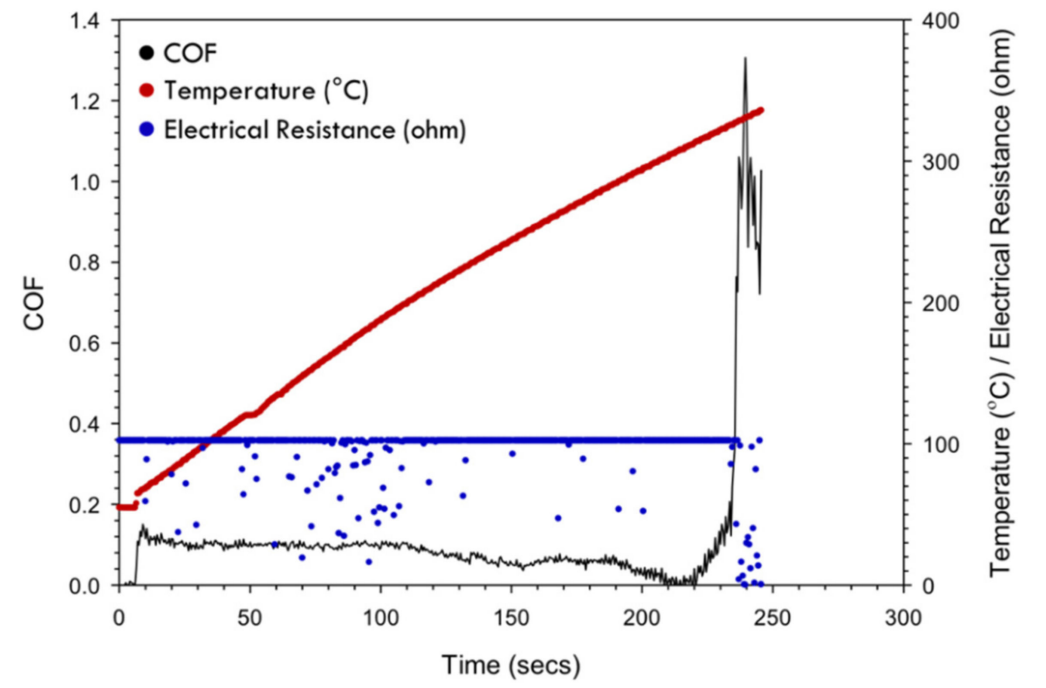

(a)

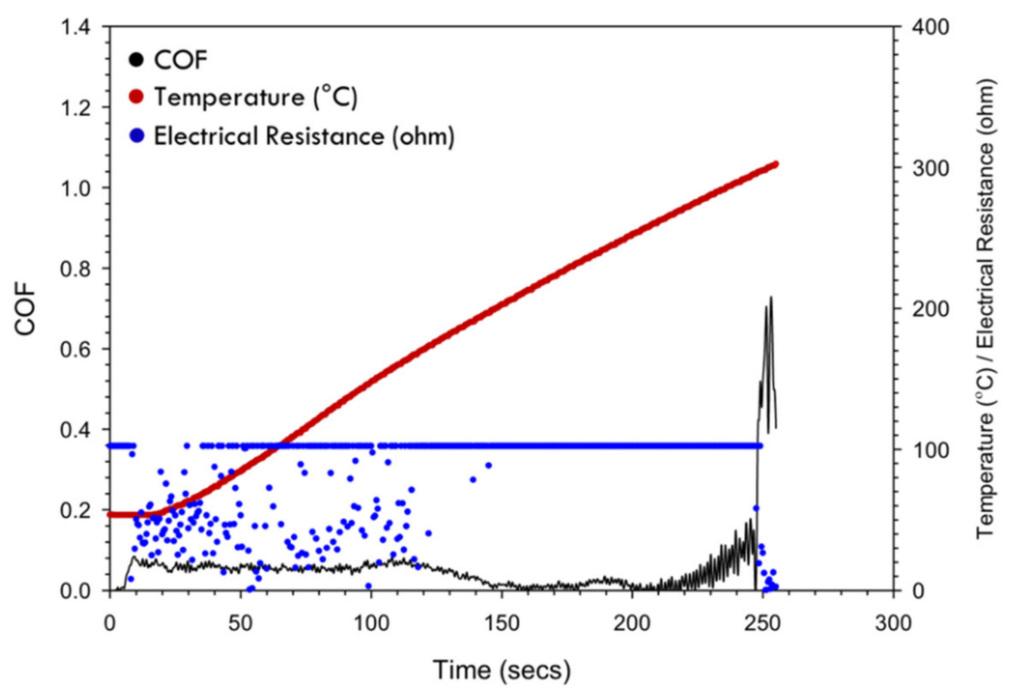

(b)

Figure 2. The $\mathrm{COF}$, temperature, and electrical resistance variation against time plot for ball-on-disc tests with an Al-Mn alloy lubricated with (a) CF A and (b) CF B under $3 \mathrm{~N}$.

The COF behavior of the cutting fluids during tests to determine the lubrication failure temperature prompted further ball-on-disc tests at constant temperatures to confirm COF reduction for the cutting fluids at elevated temperatures. Ball-on-disc tests were performed at 100,200 , and $300{ }^{\circ} \mathrm{C}$ under loads of $3 \mathrm{~N}$ and $5 \mathrm{~N}$. The COF values of each test were recorded, the average values were calculated and presented in Figure 3. The COF values of the cutting fluid additives varied with the temperature tested. Figure 3 displays the $\mathrm{COF}$ values recorded under the $3 \mathrm{~N}$ load. At $100^{\circ} \mathrm{C}, \mathrm{CF}$ A and $\mathrm{CF}$ B displayed comparable COF values at $0.057 \pm 0.001$ and $0.05 \pm 0.007$, respectively. The lowest COF value for $\mathrm{CF} B$ $(0.024 \pm 0.002)$ was observed at $200{ }^{\circ} \mathrm{C}$. However, the COF for CF A $(0.052 \pm 0.002)$ at this temperature was comparable to the $\mathrm{COF}$ observed at $100{ }^{\circ} \mathrm{C}$. At $300{ }^{\circ} \mathrm{C}$, the $\mathrm{COF}$ for $\mathrm{CF} \mathrm{A}$ was $0.867 \pm 0.020$ and $0.924 \pm 0.010$ for $C F$ B. Therefore, similar to the lubrication failure temperature tests, under the load of $3 \mathrm{~N}, \mathrm{CF}$ A displayed comparable COF at $100{ }^{\circ} \mathrm{C}$ and $200{ }^{\circ} \mathrm{C}$, while CF B displayed a reduction in COF at $200{ }^{\circ} \mathrm{C}$ in comparison to the COF at $100{ }^{\circ} \mathrm{C}$. Therefore, at $3 \mathrm{~N}$, the $\mathrm{COF}$ values for the cutting fluid additive were comparable at $100{ }^{\circ} \mathrm{C}$; at $200{ }^{\circ} \mathrm{C}, \mathrm{CF}$ B showed lower COF, while at $300^{\circ} \mathrm{C}, \mathrm{CF}$ A displayed lower COF. 


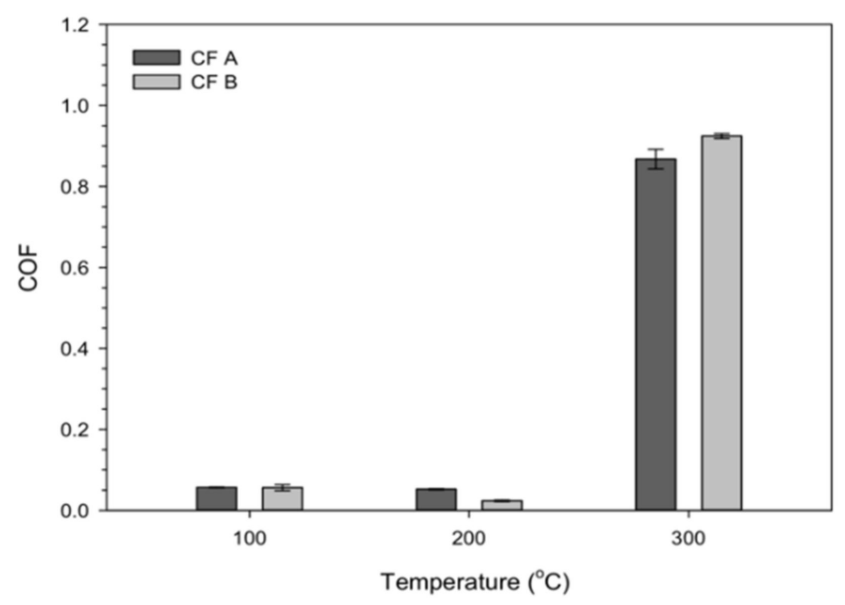

(a)

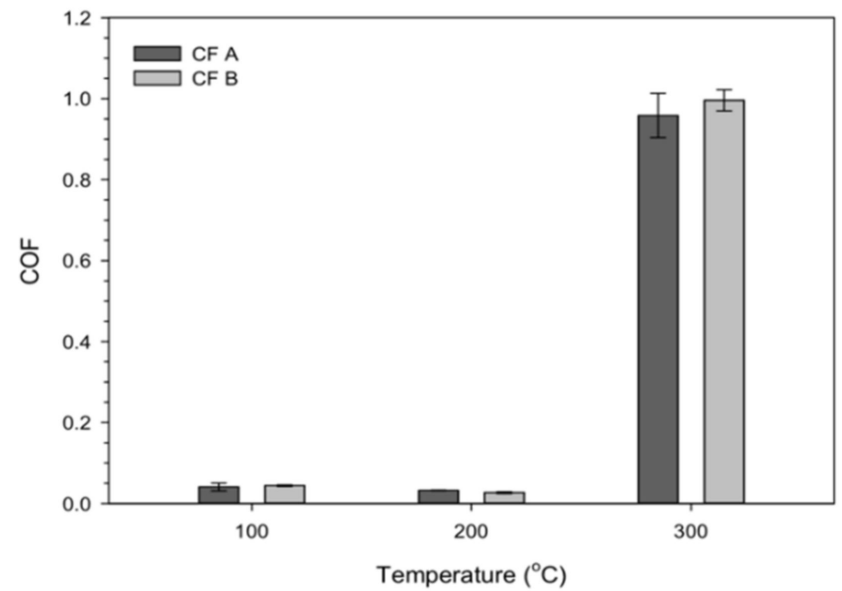

(b)

Figure 3. The average COF for Al-Mn samples against AISI 52100 steel ball with CF A and CF B at $100{ }^{\circ} \mathrm{C}, 200{ }^{\circ} \mathrm{C}$, and $300{ }^{\circ} \mathrm{C}$ under (a) $3 \mathrm{~N}$ and (b) $5 \mathrm{~N}$ applied loads.

Figure $3 \mathrm{~b}$ presents the COF data for tests at the load of $5 \mathrm{~N}$. CF A and CF B displayed their lowest COF at $200{ }^{\circ} \mathrm{C}$, at $0.032 \pm 0.001$ and $0.027 \pm 0.002$, respectively. At $300{ }^{\circ} \mathrm{C}$, the highest $\mathrm{COF}$ was for $\mathrm{CF} A$ at $0.958 \pm 0.060$ and $\mathrm{CF} \mathrm{B}$ at $0.996 \pm 0.030$. It is interesting to note the distinct reduction of $\mathrm{COF}$ at $200^{\circ} \mathrm{C}$ for $\mathrm{CF}$ B, similar to that observed for $3 \mathrm{~N}$. Moreover, similar to the trend observed for $3 \mathrm{~N}, \mathrm{CF}$ A and CF B possessed comparable COF at $100{ }^{\circ} \mathrm{C}$, while at $200^{\circ} \mathrm{C}, \mathrm{CF}$ B displayed the lower $\mathrm{COF}$, and at $300^{\circ} \mathrm{C}, \mathrm{CF}$ A possessed the lower COF. It should be noted that the low COF at $200{ }^{\circ} \mathrm{C}$ for $\mathrm{CF} B$ occurred for a shorter sliding distance for $3 \mathrm{~N}$ and $5 \mathrm{~N}$, with failure occurring at $6.62 \mathrm{~m}$ and $6.5 \mathrm{~m}$, respectively. All other tests were able to run for the $16.55 \mathrm{~m}$ sliding distance.

In summary, the COF behavior of CF A and CF B highlighted the CF A displayed a higher lubrication failure temperature. However, it displayed only a slight reduction in COF at about $290{ }^{\circ} \mathrm{C}$, while CF B displayed a significant reduction in COF at $200{ }^{\circ} \mathrm{C}$. Therefore, CF B possessed significantly lower COF than CF A from $200^{\circ} \mathrm{C}$. This would indicate that the COF behavior of $\mathrm{CF} B$ is temperature-dependent and could explain the variation in SCE during drilling under different conditions.

\subsection{Analysis of the Sliding Tracks Induced on the Al-Mn Alloy Surface}

The Al-Mn sample surfaces were examined after the ball-on-disc tests to ascertain the damage on the sliding tracks and determine the mechanisms of friction performance. SEM images of the sliding tracks on the Al-Mn surface are displayed in Figures 4-7. SEM examination of the sliding tracks on the Al-Mn surface tested with CF A (Figure 4) revealed 
an increase in surface damage within the sliding track with temperature increase. Figure 4 shows wider sliding tracks occurring at higher temperatures for CF A. Increased wear damage at the center of the siding track caused it to appear rougher than the outer regions at $200{ }^{\circ} \mathrm{C}$ (Figure 4b), while at $300{ }^{\circ} \mathrm{C}$ (Figure 4c), more severe damage was observed towards the inner portion of the sliding track. The sliding tracks induced on the Al-Mn surface possessed a smoother surface with the CF B at $100{ }^{\circ} \mathrm{C}$ (Figure 5a) and $200{ }^{\circ} \mathrm{C}$ (Figure 5b). At $300^{\circ} \mathrm{C}$, surface damage was more severe and covered a larger portion of the sliding tracks induced with CF B (Figure 5c) in comparison to sliding damage induced with CF A on the Al-Mn sample. At higher magnification, wear scars were observed within the sliding tracks on Al-Mn surfaces at $100{ }^{\circ} \mathrm{C}$ for both CF A (Figure 6a) and CF B (Figure 7a). At $200{ }^{\circ} \mathrm{C}$, the rougher regions within the sliding tracks from CF A (Figure $6 \mathrm{~b}$ ) were revealed to be due to damage in the form of deeper wear scars appearing as grooves and ridges, an indication of abrasive wear. The surface of the sliding track at $200{ }^{\circ} \mathrm{C}$ for CFB (Figure $7 \mathrm{~b}$ ) was smoother compared to all other sliding tracks at other conditions and induced by the other additive. There was little surface damage observed within the sliding track at this condition. However, polymerized lubricant was observed lying on the surface within the sliding track. A comparison of the regions with the highest surface damage induced at $300{ }^{\circ} \mathrm{C}$ revealed wear grooves overlapped for CF A (Figure 6c) and CF B (Figure $7 \mathrm{~b}$ ), indicating severe wear and plastic deformation. The widths of the sliding tracks on the Al-Mn surfaces were measured for both loads and graphically presented in Figure 8. The sliding track widths on the Al-Mn surface induced by CF B were generally lower than those induced with CF A under $3 \mathrm{~N}$ load. The variance in sliding track widths was much greater at $200{ }^{\circ} \mathrm{C}$ than at other temperatures the cutting fluid additives were tested. The widths of the sliding track were observed to increase with the increase in temperature for CF A. However, the sliding track widths with CF B were comparable at $100{ }^{\circ} \mathrm{C}(249.94 \pm 11.41 \mu \mathrm{m})$ and $200{ }^{\circ} \mathrm{C}(258.71 \pm 15.50 \mu \mathrm{m})$, but highest at $300{ }^{\circ} \mathrm{C}(1607.70 \pm 113.78 \mu \mathrm{m})$. Under $5 \mathrm{~N}$, the highest disparity between the sliding track widths of the two cutting fluid additives was observed at $300{ }^{\circ} \mathrm{C}(2349.32 \mu \mathrm{m}$ for CF A and $1799.84 \mu \mathrm{m}$ for CF B). Again, the sliding track widths were observed to increase with the increase in temperature for CF A, while the lower disparity in sliding track widths was observed at $100{ }^{\circ} \mathrm{C}(405.87 \pm 15.89 \mu \mathrm{m})$ and $200{ }^{\circ} \mathrm{C}(500.66 \pm 72.30 \mu \mathrm{m})$ for $\mathrm{CF}$ B. Generally, the sliding track widths were observed to be higher with the increase in applied loads for both cutting fluid additives. The sliding track width at $300{ }^{\circ} \mathrm{C}$ was six times the sliding track widths at $100{ }^{\circ} \mathrm{C}$ for both cutting fluid additives under $3 \mathrm{~N}$ and four times higher at $5 \mathrm{~N}$. The standard deviation of the sliding track widths was also high at $300{ }^{\circ} \mathrm{C}$ for both cutting fluid additives under both loads, indicating the high disparity of the widths of the sliding track at this temperature.

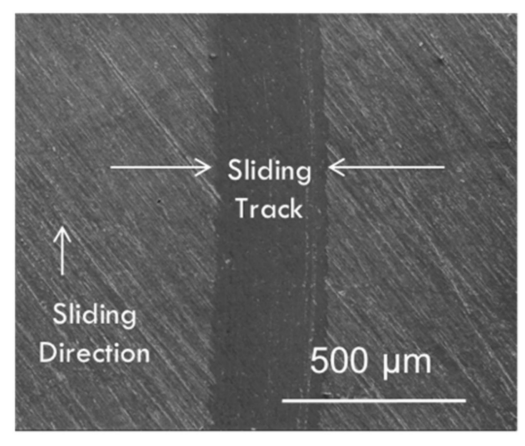

(a)

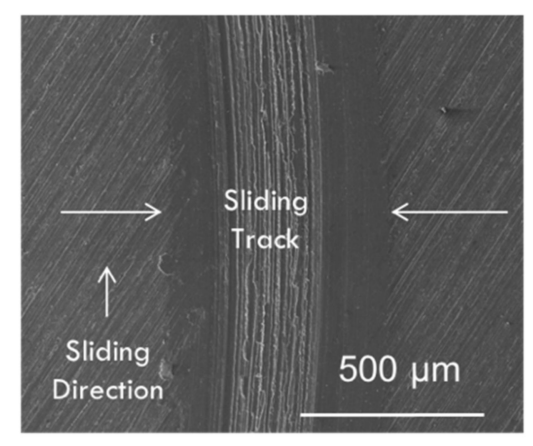

(b)

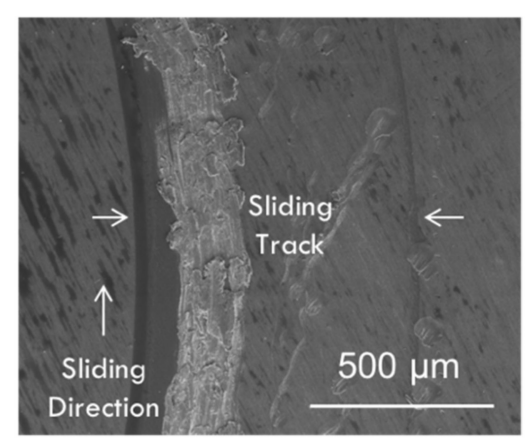

(c)

Figure 4. Secondary electron images of sliding tracks induced with CF A at (a) $100{ }^{\circ} \mathrm{C},(\mathbf{b}) 200{ }^{\circ} \mathrm{C}$, and (c) $300{ }^{\circ} \mathrm{C}$ under the load of $3 \mathrm{~N}$. 


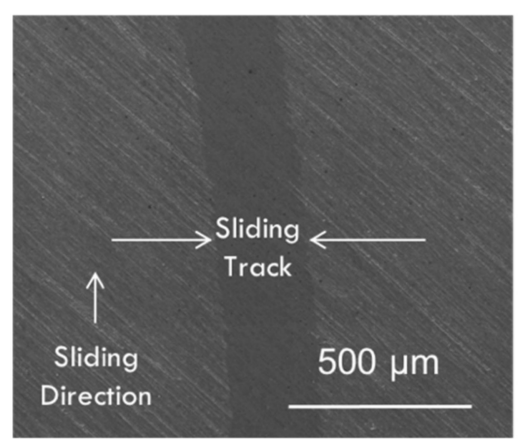

(a)

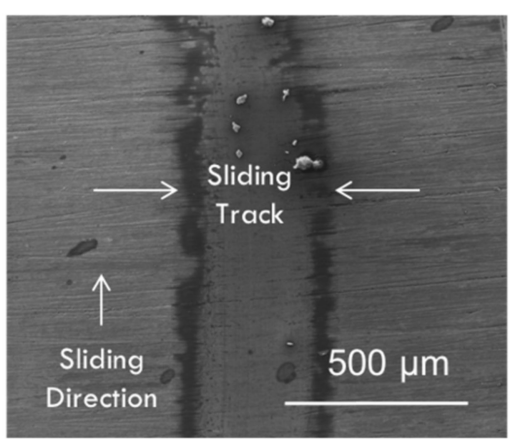

(b)

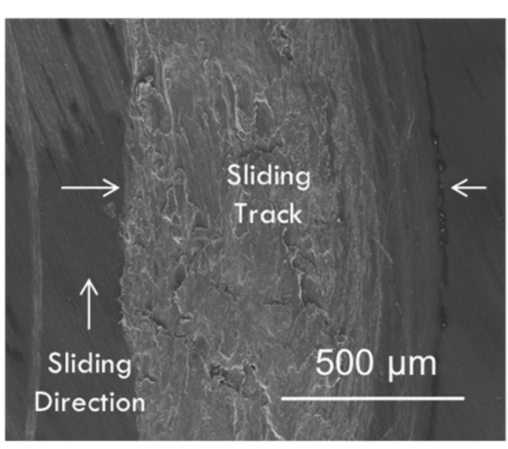

(c)

Figure 5. Secondary electron images of sliding tracks induced with $\mathrm{CF} B$ at (a) $100{ }^{\circ} \mathrm{C},(\mathbf{b}) 200{ }^{\circ} \mathrm{C}$, and (c) $300{ }^{\circ} \mathrm{C}$ under the load of $3 \mathrm{~N}$.

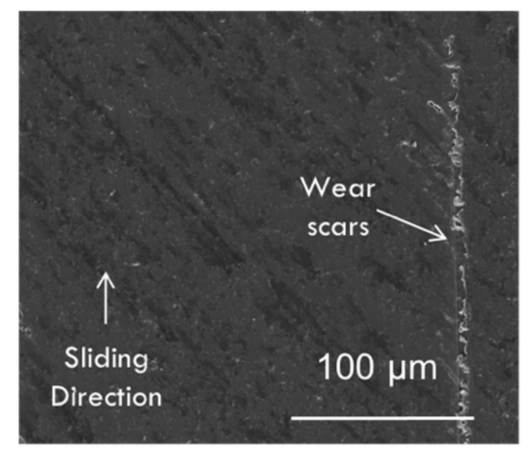

(a)

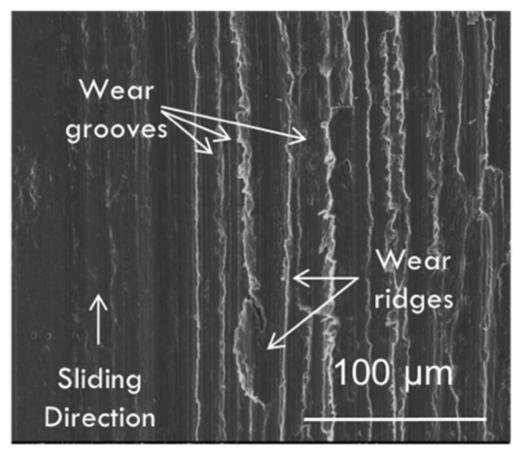

(b)

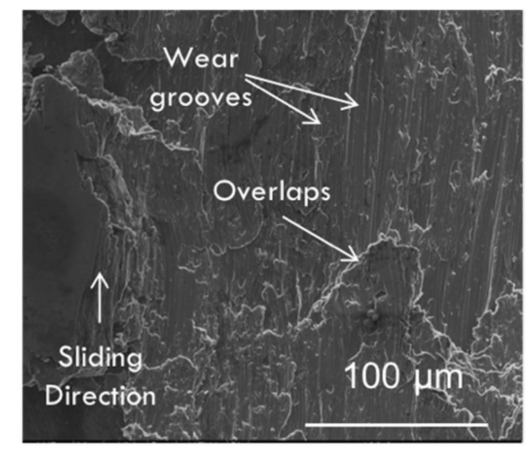

(c)

Figure 6. Secondary electron images of surface damage within the sliding tracks induced with $\mathrm{CF}$ A at (a) $100{ }^{\circ} \mathrm{C},(\mathbf{b}) 200{ }^{\circ} \mathrm{C}$, and (c) $300^{\circ} \mathrm{C}$ under the load of $3 \mathrm{~N}$.

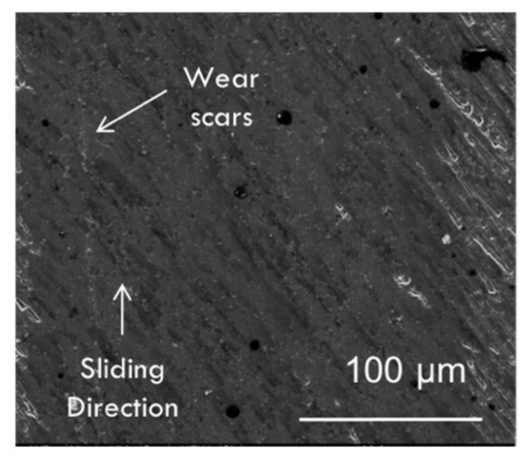

(a)

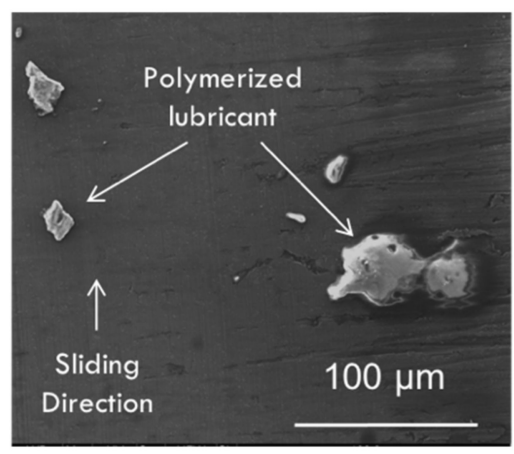

(b)

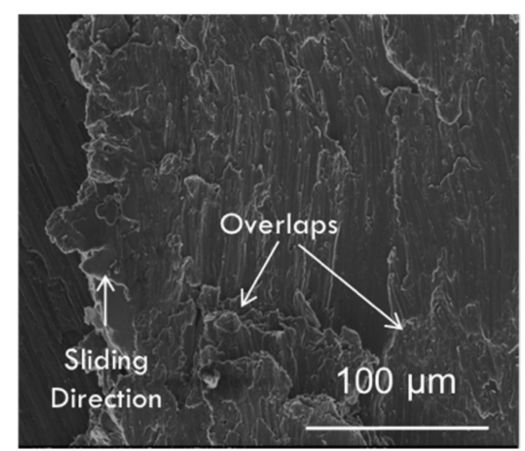

(c)

Figure 7. Secondary electron images of the surface damage within the sliding tracks induced with $\mathrm{CF}$ B at (a) $100{ }^{\circ} \mathrm{C}$, (b) $200{ }^{\circ} \mathrm{C}$, and (c) $300{ }^{\circ} \mathrm{C}$ under the load of $3 \mathrm{~N}$. 


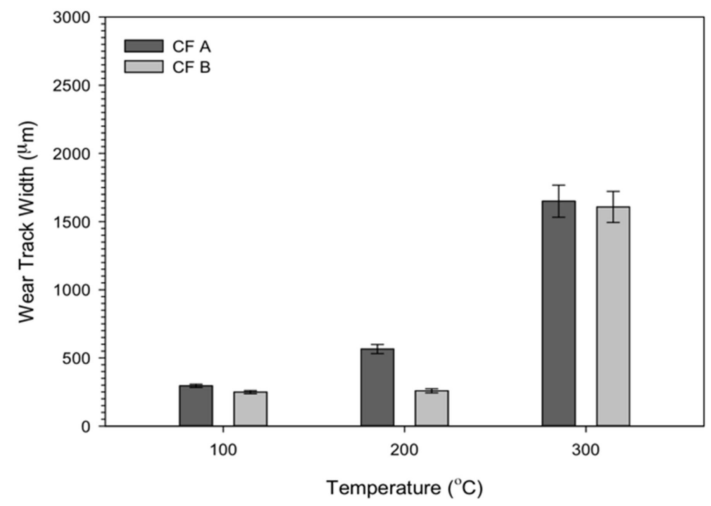

(a)

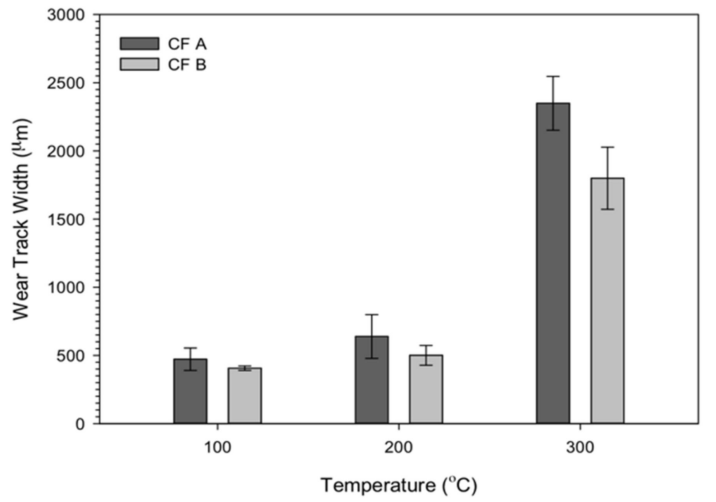

(b)

Figure 8. The plot of sliding track widths induced on the Al-Mn surface against temperature for both cutting fluid additives under loads of (a) $3 \mathrm{~N}$ and (b) $5 \mathrm{~N}$.

The surface analysis on the Al-Mn discs (Figure 9) after failure in tests to determine the critical temperature (Tc) of lubrication failure displayed wider sliding tracks on the Al-Mn surface used with CF A $(1302.20 \pm 95.39 \mu \mathrm{m})$ than those induced for the CF B $(1164.80 \pm 165.60 \mu \mathrm{m})$. Surface damage was observed within the sliding tracks from both additives (Figure 10) in the form of delamination, material overlaps, and cracks for both CF $\mathrm{A}$ and $\mathrm{CF} B$ indicative of severe wear associated with failure. However, a greater portion of the outer regions of the sliding track for CF B was smoother and possessed less damage, while the delamination and material overlaps were noted for less than half of the sliding track width $(563.64 \pm 69.39 \mu \mathrm{m})$.

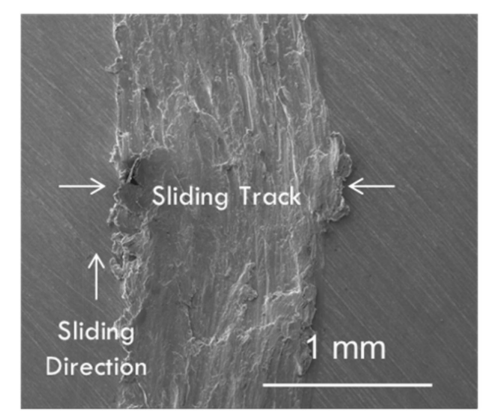

(a)

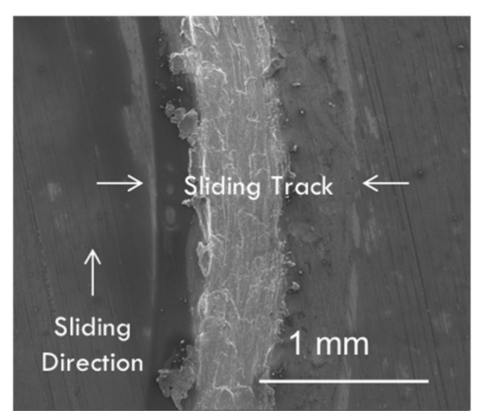

(b)

Figure 9. Secondary electron images displaying the sliding tracks induced on the Al-Mn surface at the critical temperature with (a) CF A and (b) CF B under $3 \mathrm{~N}$.

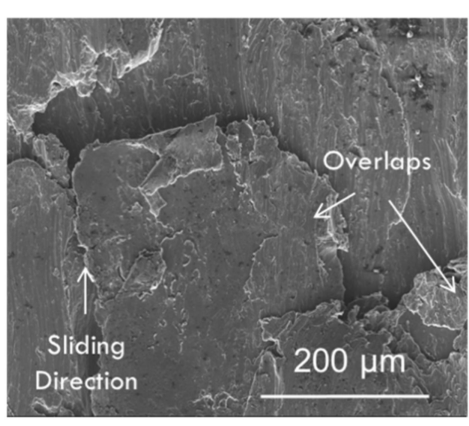

(a)

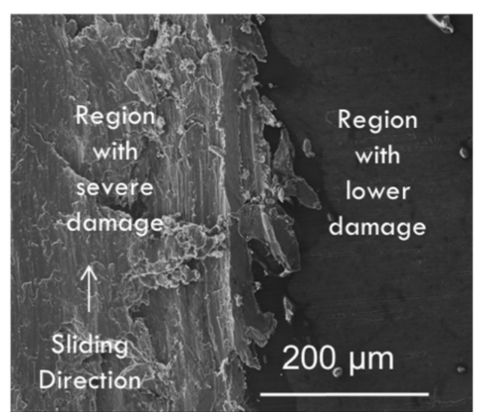

(b)

Figure 10. Secondary electron images displaying the surface damage features within the sliding tracks induced on the Al-Mn surface at the critical temperature with (a) CF A and (b) CF B under $3 \mathrm{~N}$. 
Energy dispersive spectrometry (EDS) mapping was employed to detect the elemental composition of the sliding tracks on the Al-Mn surface and the material transfer to the steel balls as well as identify the distribution of these elements on the surface. The EDS maps of the Al-Mn sliding track are displayed in Figures 11 and 12. The maps identified the aluminum, carbon, oxygen, and phosphorus within the sliding tracks. Figure 11a displays the maps of the sliding track induced on the Al-Mn surface used with CF A at $100{ }^{\circ} \mathrm{C}$. The elemental distribution showed carbon covering the sliding track as well as a correlation between aluminum and oxygen. Small carbon agglomerates were also observed sporadically dispersed within the sliding track. The sliding track of the CF B (Figure 12a) displayed randomly dispersed thicker carbon-rich packets within the thin carbon layer covering the sliding track. A correlation between oxygen and aluminum was also noted. At $200{ }^{\circ} \mathrm{C}$, carbon and oxygen distribution was observed to be highly concentrated on the ridges of the wear scars induced on the sliding track with CF A (Figure 11b). The Al-Mn surface tested with CF B (Figure 12b) displayed carbon-rich areas which corresponded with the polymerized lubricant and darker regions observed on the SEM image in Figure 5b. The carbon corresponded with oxygen as well as aluminum deficient areas on the EDS maps. The phosphorus map displayed enrichment in regions corresponding primarily with the carbon located within the darker regions (Figure 12b). The distribution of phosphorus and carbon observed in these maps highlighted that a phosphorus-infused tribolayer had been formed on the track surface. The analysis on the Al-Mn surface at $300{ }^{\circ} \mathrm{C}$ showed oxygen deficiency occurring within deep grooves of the sliding track used with both CF A and CF B, while carbon distribution was dispersed in random packets within the sliding track (Figures 11 and 12c).
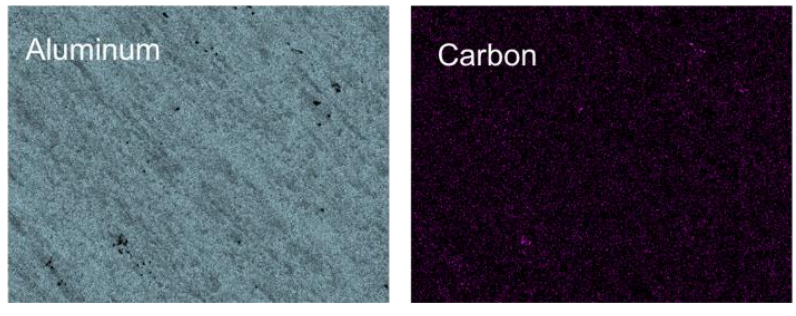

(a)
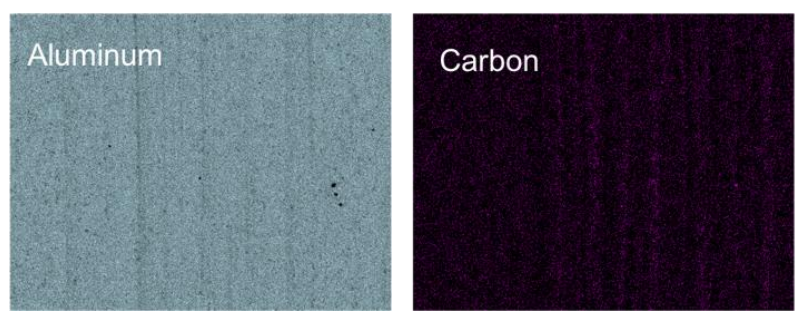

(b)
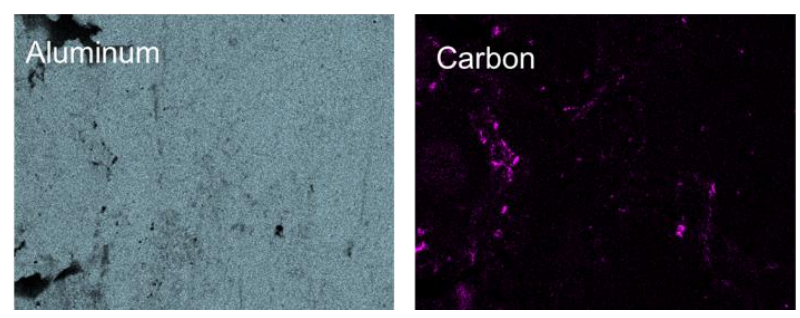
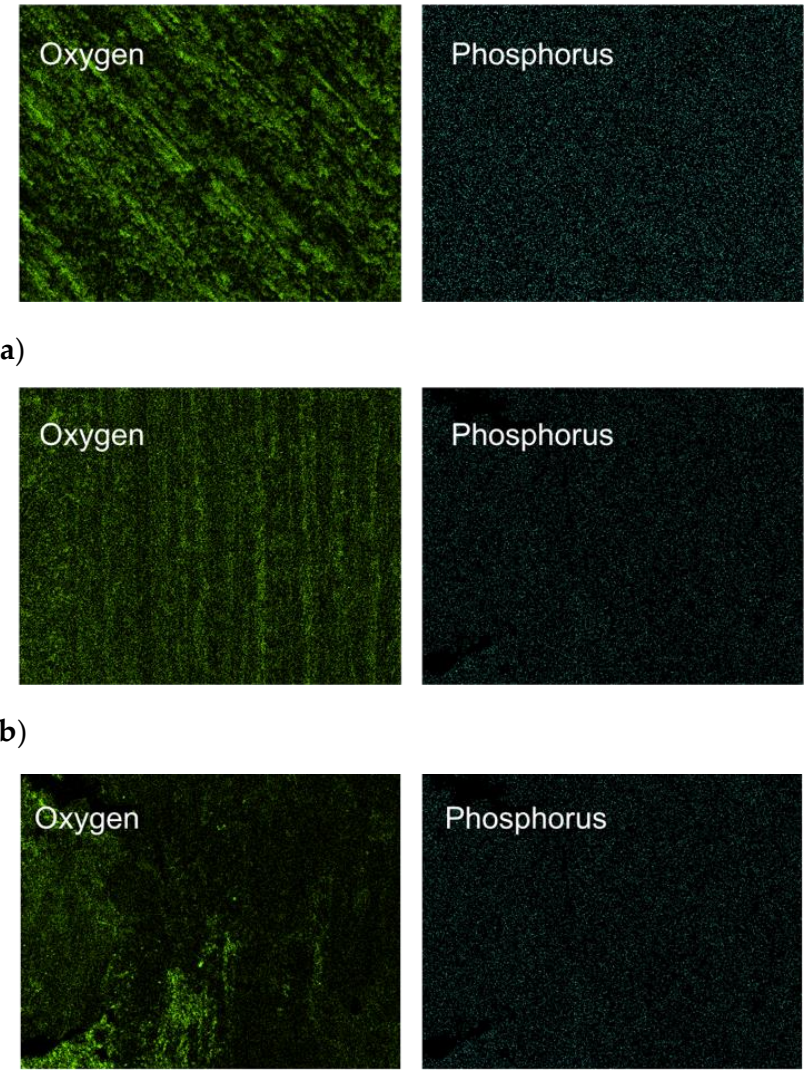

(c)

Figure 11. EDS maps displaying the elemental distribution of tribolayers formed within the sliding tracks on the Al-Mn surfaces tested against AISI 52100 steel lubricated with CF A at (a) $100{ }^{\circ} \mathrm{C}$, (b) $200{ }^{\circ} \mathrm{C}$, and (c) $300{ }^{\circ} \mathrm{C}$. 

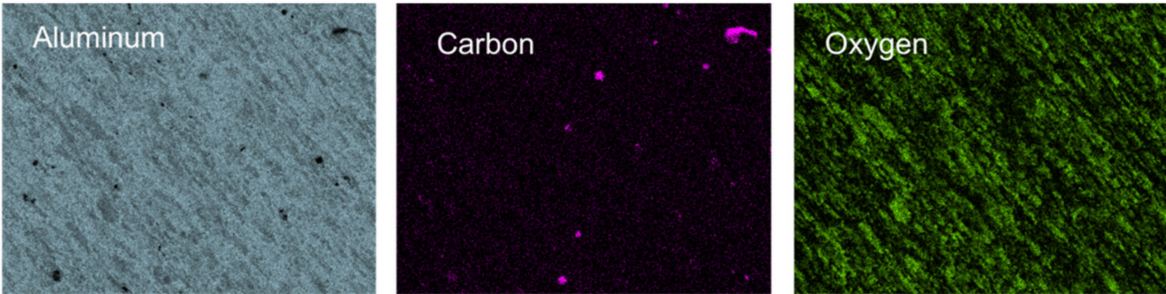

(a)
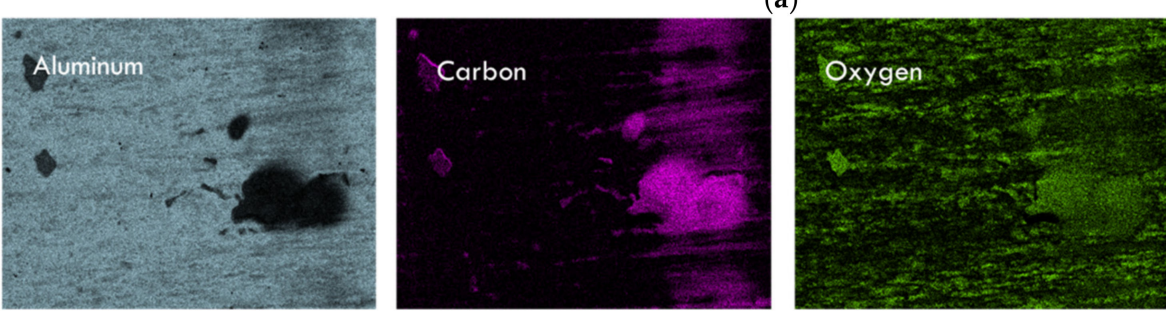

(b)
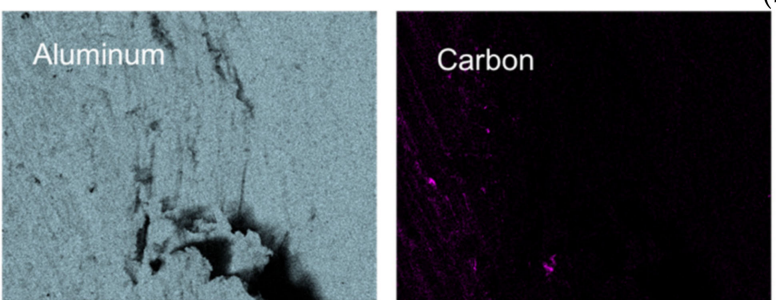
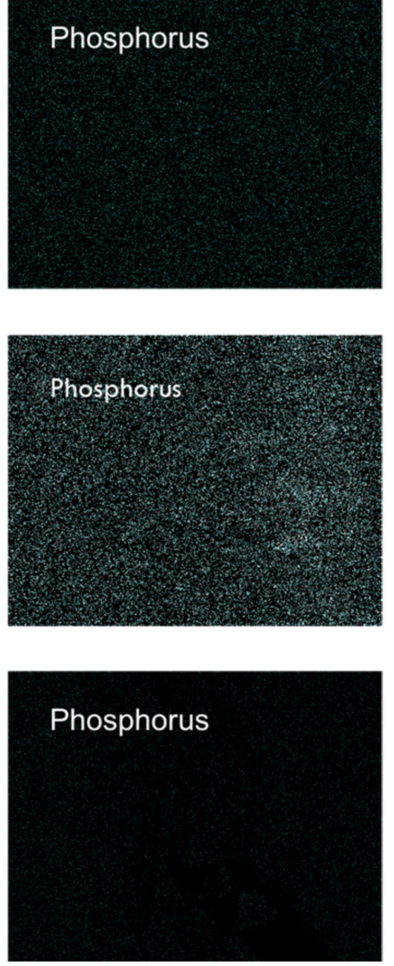

(c)

Figure 12. EDS maps displaying the elemental distribution of tribolayers formed within the sliding tracks on the Al-Mn surfaces tested against AISI 52100 steel lubricated with CF B at (a) $100^{\circ} \mathrm{C}$, (b) $200^{\circ} \mathrm{C}$, and (c) $300{ }^{\circ} \mathrm{C}$.

EDS maps obtained from the Al-Mn surface after failure for the critical temperature (Tc) tests displayed carbon underneath the overlaps within the sliding tracks induced with CF A (Figure 13), while the siding tracks induced by CF B possessed a thin layer of carbon covering its surface. The phosphorus maps revealed a lower concentration within the sliding track induced on CF A than on CF B.
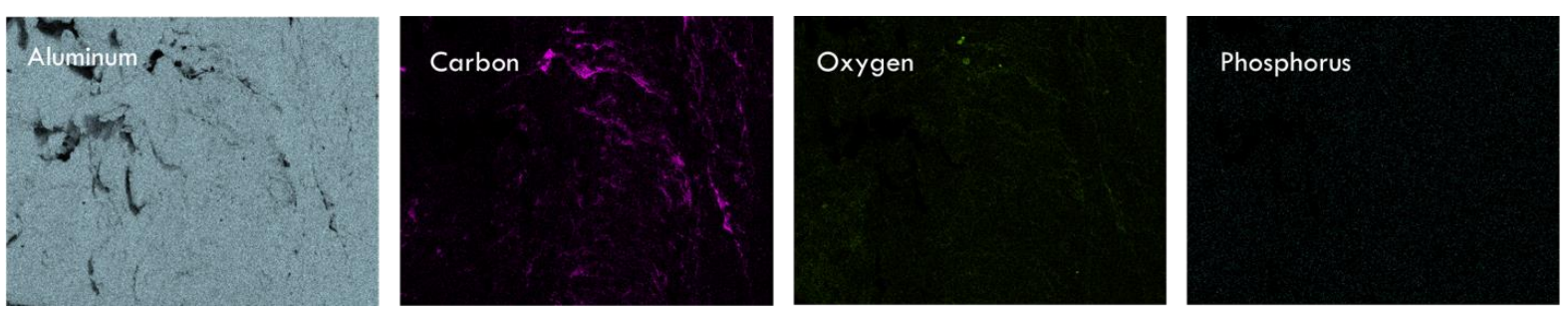

(a)
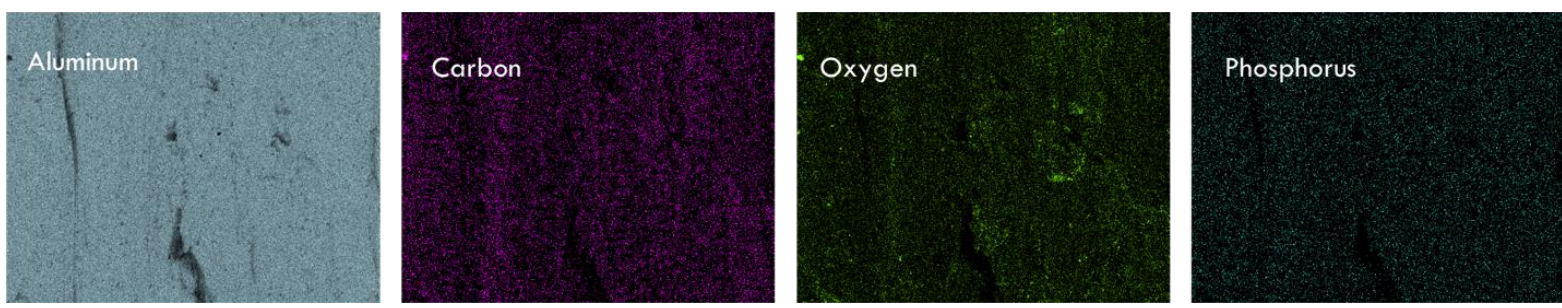

(b)

Figure 13. EDS maps displaying the elemental distribution of tribolayers formed within the sliding tracks on the Al-Mn surfaces tested against AISI 52100 steel at critical temperature lubricated with (a) CF A and (b) CF B under 3 N. 
In summary, low sliding damage was observed on the Al-Mn surface at temperatures lower than $300^{\circ} \mathrm{C}$ for both CF A and CF B. However, greater surface damage was induced with $\mathrm{CF}$ A at $200{ }^{\circ} \mathrm{C}$ in the form of abrasive wear. The lower damage below $300{ }^{\circ} \mathrm{C}$ corresponds with the carbon and phosphorus distribution on the surface. At $300{ }^{\circ} \mathrm{C}$ and during tests for lubrication failure, severe wear damage was observed, which is associated with failure during sliding contact.

\subsection{Characterization of Material Transfer on AISI 52100 Steel Counterfaces}

The surfaces of the AISI 52100 steel balls used as counterfaces during sliding contact with the corresponding Al-Mn surface tested under the applied load of $3 \mathrm{~N}$ were also examined. Material transfer on the steel ball surfaces was noted under every siding condition and is displayed after tests at 100,200 , and $300{ }^{\circ} \mathrm{C}$ for both cutting fluid additives in Figures 14 and 15 respectively. The surface area covered with material transfer could be visually observed to increase in thickness and width with the increase of the temperature for CF A. Thin layers of aluminum could be observed only at $100{ }^{\circ} \mathrm{C}$ (Figure 14a) for CF A, while aluminum build-up could be observed at $200{ }^{\circ} \mathrm{C}$ for $\mathrm{CF}$ A (Figure $14 \mathrm{~b}$ ) and $300{ }^{\circ} \mathrm{C}$ for both CF A (Figure 14c) and CF B (Figure 15c). The width of the area covered with material transfer at $100{ }^{\circ} \mathrm{C}$ (Figure 14a) was $222.58 \mu \mathrm{m}$, while at $300{ }^{\circ} \mathrm{C}$ (Figure $14 \mathrm{c}$ ), the width was at least six times in size $(1327.82 \mu \mathrm{m})$. CF B displayed the lowest width of material transfer area at $200{ }^{\circ} \mathrm{C}$ (Figure $15 \mathrm{~b}$ ) at $222.34 \mu \mathrm{m}$ (similar to the width of the $\mathrm{CF} A$ at $100^{\circ} \mathrm{C}$ ) and the highest at $300{ }^{\circ} \mathrm{C}$ (Figure 15c), where it was six times larger $(1337.84 \mu \mathrm{m})$.

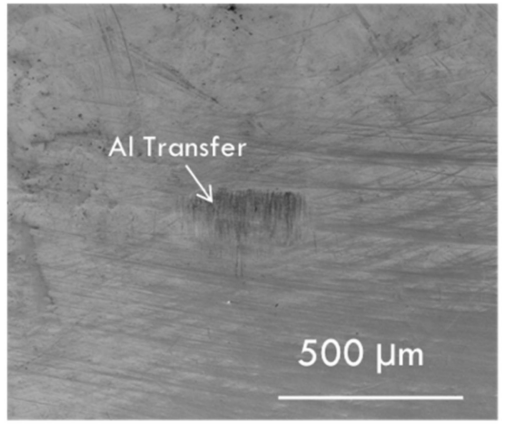

(a)

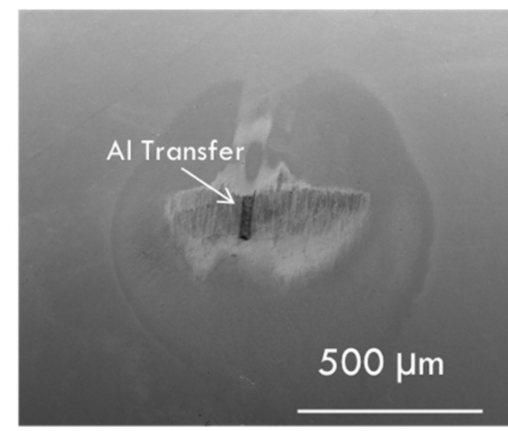

(b)

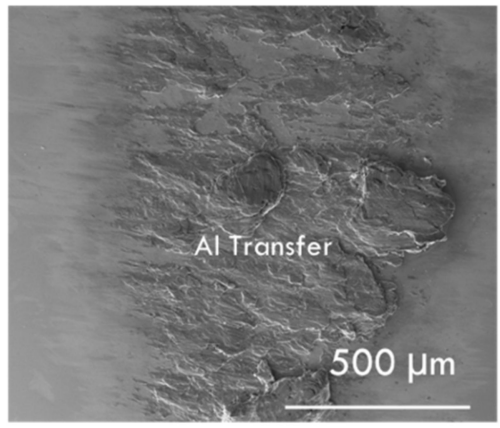

(c)

Figure 14. Secondary electron images of the AISI 52100 steel ball taken after sliding contact against Al-Mn surface used with $\mathrm{CF}$ A at (a) $100{ }^{\circ} \mathrm{C}$, (b) $200^{\circ} \mathrm{C}$, and (c) $300^{\circ} \mathrm{C}$ under the load of $3 \mathrm{~N}$.

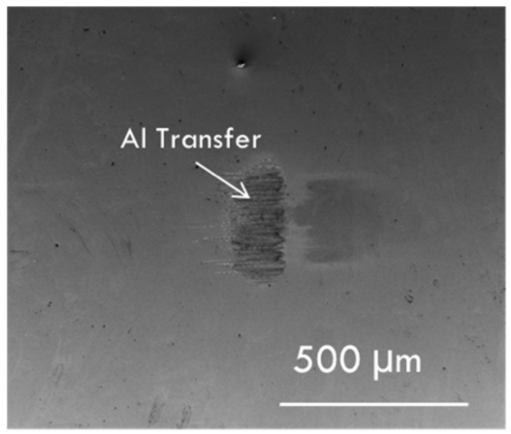

(a)

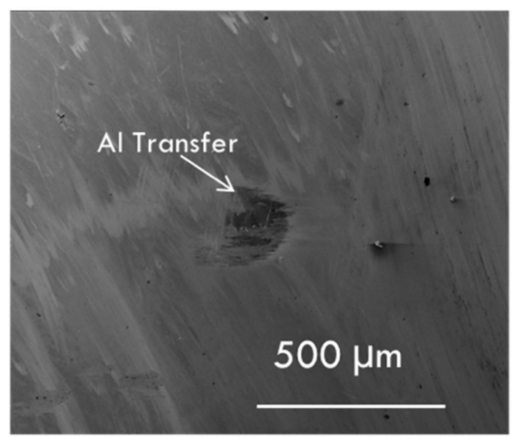

(b)

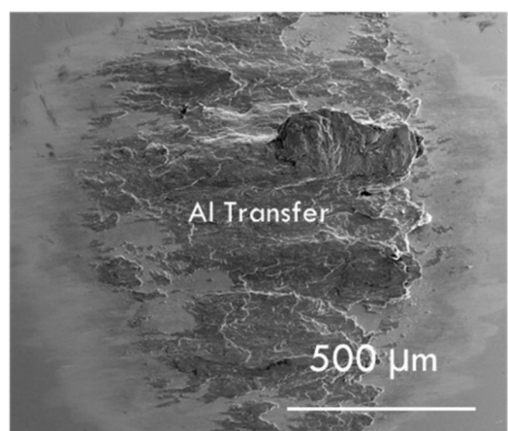

(c)

Figure 15. Secondary electron images of the AISI 52100 steel ball taken after sliding contact against Al-Mn surface used with CF B at (a) $100{ }^{\circ} \mathrm{C}$, (b) $200{ }^{\circ} \mathrm{C}$, and (c) $300{ }^{\circ} \mathrm{C}$ under the load of $3 \mathrm{~N}$.

Interestingly, the material transfer widths on the steel balls with CF B were generally higher than those with CF A at the corresponding temperatures except at $200{ }^{\circ} \mathrm{C}$. At $200^{\circ} \mathrm{C}$, 
the material transfer width for CF B was around half of that with CF A. The EDS maps from corresponding SEM images displayed the aluminum, carbon, oxygen, phosphorus, and iron on all the steel balls. The EDS maps (Figures 16 and 17) displayed aluminum transfer from the Al-Mn surface on all steel counter-surfaces. The aluminum transfer on the steel ball used with $\mathrm{CF}$ A at $100^{\circ} \mathrm{C}$ (Figure 16a) was visually observed to cover the smallest area. The EDS maps revealed a correlation of oxygen with aluminum on the steel balls run with both $\mathrm{CF} A$ and $\mathrm{CF} \mathrm{B}$ at $100^{\circ} \mathrm{C}$ and $200^{\circ} \mathrm{C}$. The thickest aluminum transfer was observed for both cutting fluid additives at $300^{\circ} \mathrm{C}$. The EDS maps revealed the oxygen-rich regions overlapped with the thinner aluminum layers at the outskirts of the aluminum transfer. However, lower oxygen concentrations and oxygen-deficient areas were observed overlapping the aluminum build-up. This indicated that the thinner layers of aluminum were oxidized while regions within the build-up were unoxidized aluminum.
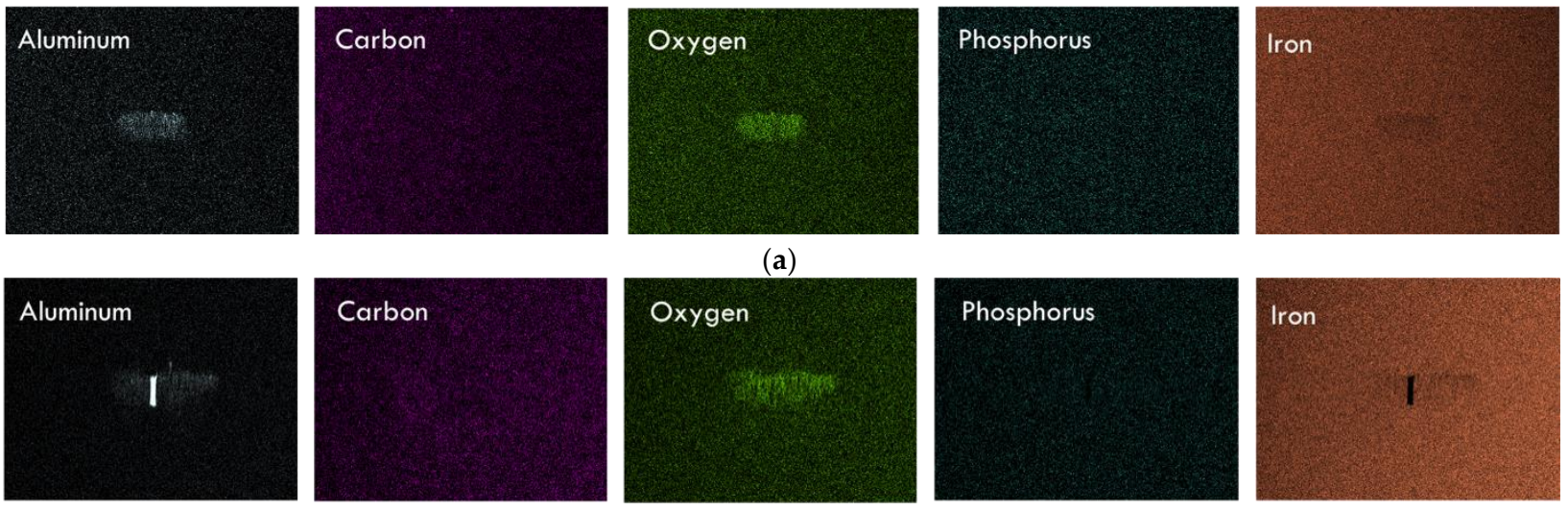

(b)
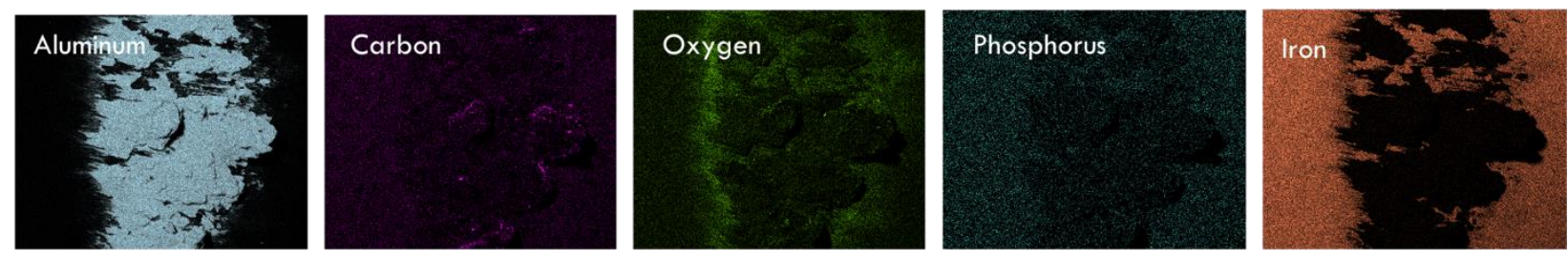

(c)

Figure 16. EDS maps displaying the elemental distribution on the AISI 52100 steel ball against Al-Mn surfaces tested with CF A at (a) $100{ }^{\circ} \mathrm{C}$, (b) $200{ }^{\circ} \mathrm{C}$, and (c) $300{ }^{\circ} \mathrm{C}$.

The SEM images (Figure 18) of the steel ball counter-surfaces after failure for the critical temperature (Tc) tests show that the build-up of aluminum transfer layer on the steel balls was thick for CF A (Figure 18a), while a thinner patchy build-up layer was noted for CF B (Figure 18b). A lower width for the material transfer was measured on the steel ball used with CF A $(545.46 \mu \mathrm{m})$ than CF B $(672.04 \mu \mathrm{m})$. The EDS maps (Figure 19) on the steel ball confirmed the aluminum transfer on the steel balls. Again, the oxygen-rich regions corresponded with the thinner aluminum layers. In contrast, a carbon-rich area was only noted at the overlaps of the thicker aluminum build-up. Phosphorus was also observed overlapping the thinner aluminum build-up of CF B on the steel ball surface (Figure 19b). 

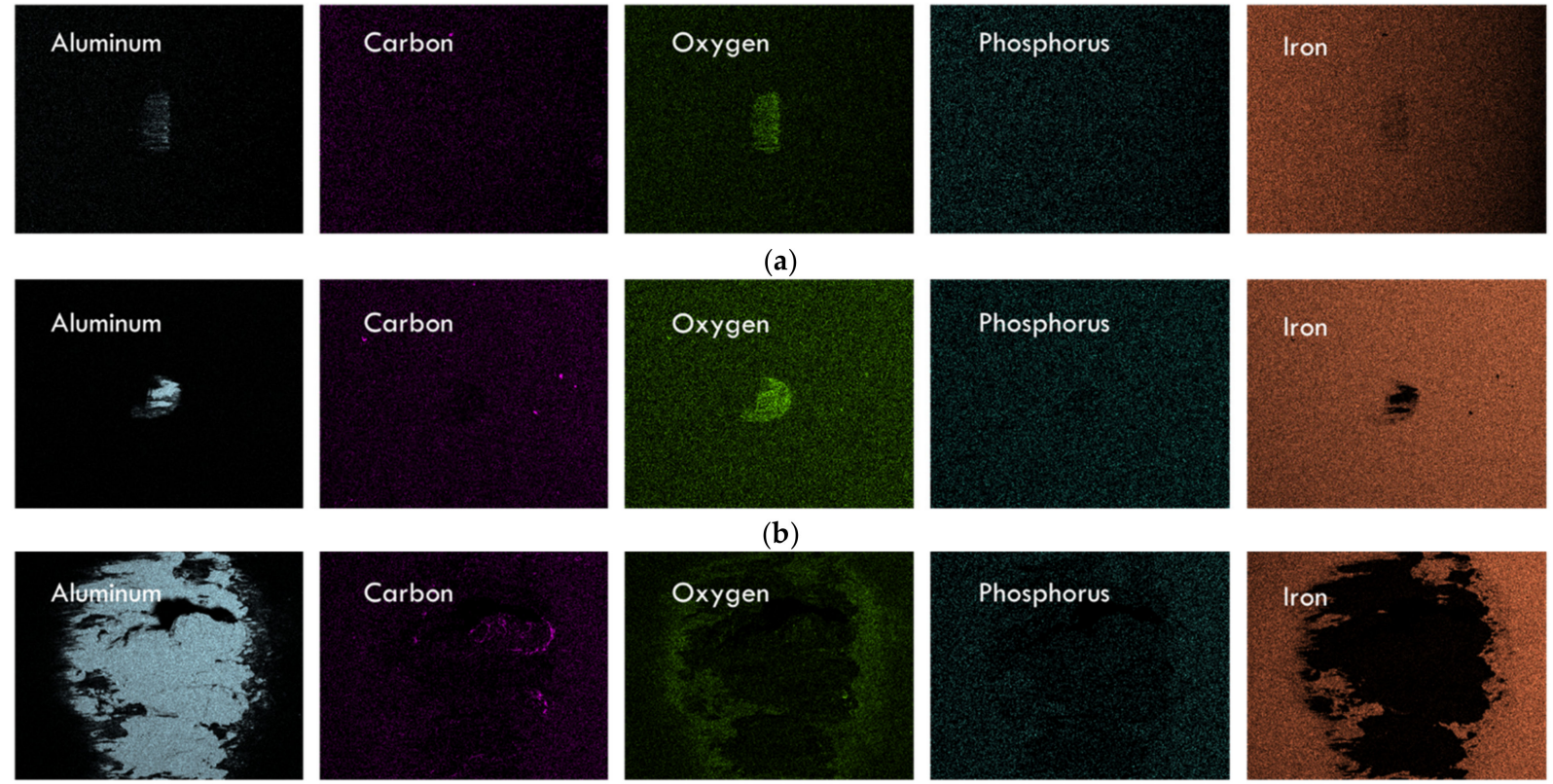

(a)
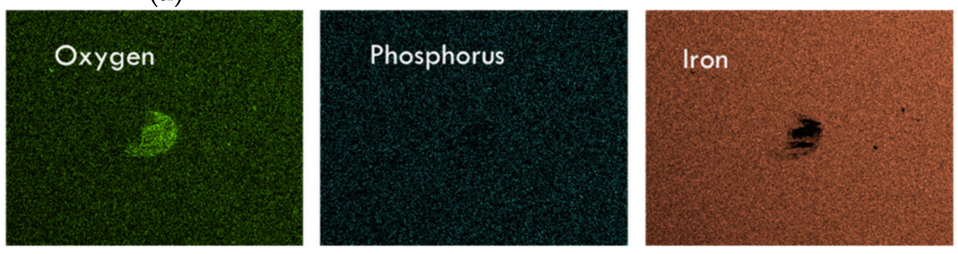

(b)
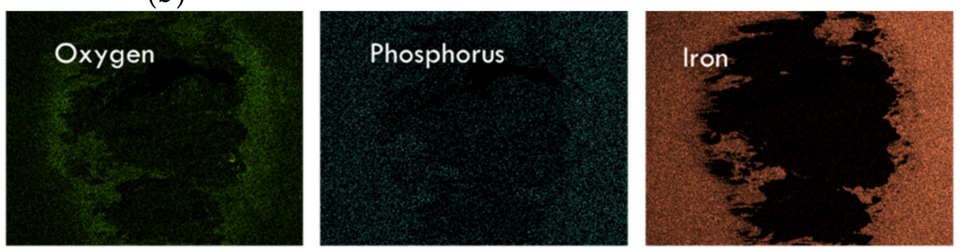

(c)

Figure 17. EDS maps displaying the elemental distribution on the AISI 52100 steel ball against Al-Mn surfaces tested with CF B at (a) $100{ }^{\circ} \mathrm{C},(\mathbf{b}) 200^{\circ} \mathrm{C}$, and (c) $300{ }^{\circ} \mathrm{C}$.

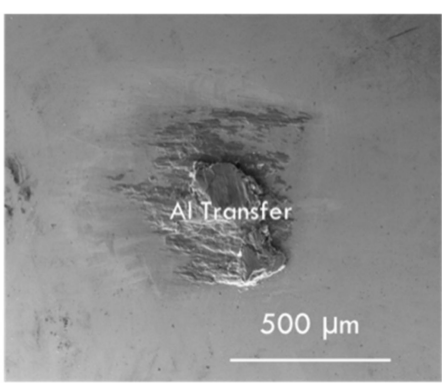

(a)

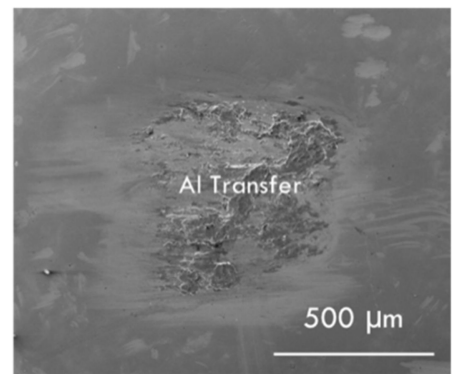

(b)

Figure 18. Secondary electron images of the AISI 52100 steel ball taken after sliding contact against Al-Mn surface at critical temperature with (a) CF A and (b) CF B under $3 \mathrm{~N}$.
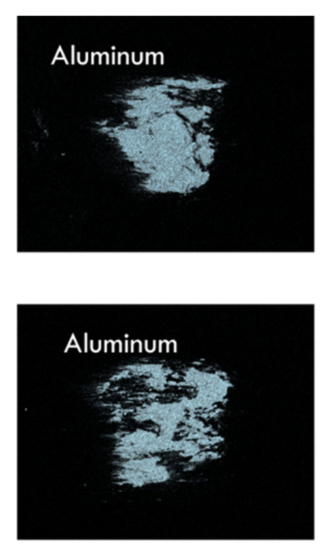

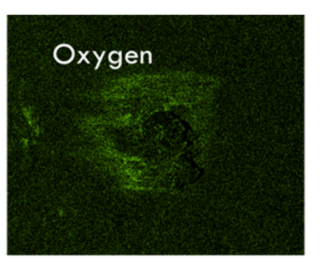

(a)
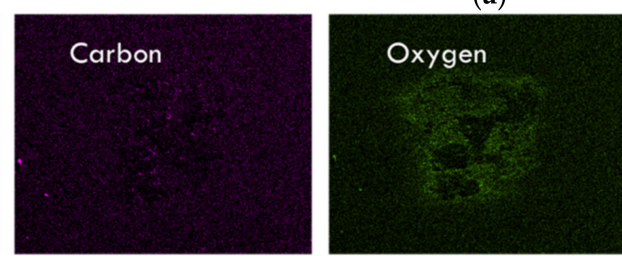
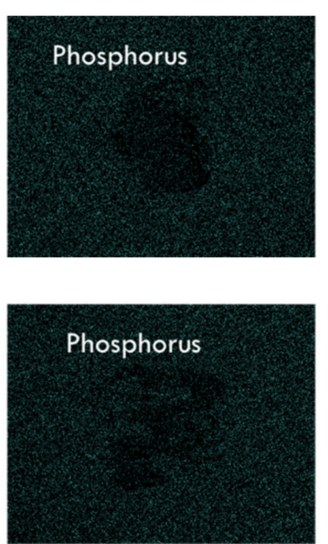
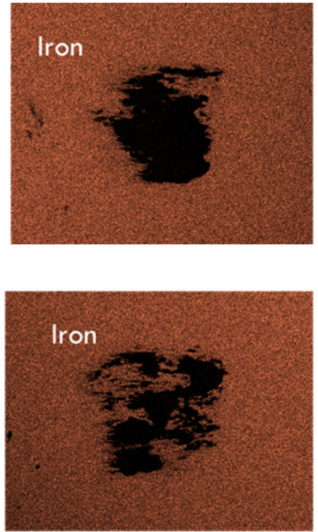

(b)

Figure 19. EDS maps displaying the elemental distribution on the AISI 52100 steel ball against Al-Mn surfaces at critical temperature with (a) CF A and (b) CF B under $3 \mathrm{~N}$. 
In summary, aluminum adhesion was observed on all the steel counterfaces regardless of the test's temperature. However, the surface area covered with adhesion increased as temperature increased. Aluminum adhesion build-up was observed on the steel ball surfaces at $300{ }^{\circ} \mathrm{C}$ and after lubrication failure.

\section{Discussion}

Ball-on-disc tests were used to examine the tribological behavior of phosphorus-based and polymer-based cutting fluid additives. The lubrication failure tests were performed by constantly increasing the temperature during the ball-on-disc tests to determine the critical temperature of the additives. The novelty of this approach in examining the tribological behavior of cutting fluid additives is the insights it offers into the changes in the behavior of the additives as temperatures increase. The insights gained are readily applicable to the machining operation where tool temperatures are rarely constant. During drilling, temperatures can steadily or quickly rise from room temperatures to elevated drilling temperatures as each hole is drilled or as the number of holes increases. Adhesion due to metal-to-metal contact is known to cause the build-up and loss of BUE, which can either aid or hinder the drilling process. Therefore, the variation in the tribological behavior of the cutting fluid as temperatures increase would prove vital in determining the efficiency of the cutting fluid during the drilling operations. Lubrication failure tests offer a better understanding of the influence that increasing temperatures have on the tribological behavior of the cutting fluid additive. The lubrication failure of the phosphorus-based additive occurred at a lower critical temperature (Tc) than the polymer-based additive. This would highlight that during the operation (i.e., machining) of Al alloys, the polymer-based additive would withstand higher cutting temperatures than the phosphorus-based additive. Workpiece temperature during dry drilling of aluminum alloys has been reported to reach about $271^{\circ} \mathrm{C}$. While the phosphorus-based additive displayed a closer Tc to the dry drilling workpiece temperatures, the polymer-based additive was well above it. Lubrication failure resulted in severe wear damage to the Al-Mn surface as well as aluminum build-up on the steel ball surface. The material overlaps observed on the aluminum surface were due to plastic deformation, material displacement, and ploughing due to the increased softening of the Al-Mn surface at this temperature. The failure of lubrication resulted in increased aluminum adhesion to the steel ball surface, and in turn the adhered material on the steel surface induced the grooves within the wear track through ploughing (Figures 10 and 18). However, it should be noted that a major function of cutting fluids is to provide cooling in addition to lubrication. Thus, lower drilling temperatures would be expected during lubricated drilling.

Regardless, the higher Tc of the polymer-based additive highlights that this additive would display better performance than phosphorus-based additive under more extreme tribological conditions, where higher temperatures are experienced. This would be a result of the lubrication failure of the phosphorus-based additive under these conditions. The failure of each cutting fluid additive would be due to the oil-in-water fluid's inability to release the oil within the tribological interface at the critical temperatures and not the actual failure of the cutting fluid oil. The neat oils used for the emulsions CF A and CF B possessed much higher critical temperatures than the oil-in-water fluids and displayed a better ability to hinder metal-to-metal contact, as seen in Figure 20. However, the critical temperature of the phosphorus-based additive $\left(\sim 422{ }^{\circ} \mathrm{C}\right)$ was still lower than that of the polymer-based additive $\left(\sim 448^{\circ} \mathrm{C}\right)$. The results observed here correlate with previous work [18], which showed that the polymer-based additive performed better than the phosphorus-based additive under high speed/low feed rate drilling conditions, showing failure for the phosphorus-based additive under extreme conditions. The improved performance of the polymer-based additive at higher temperatures was likely due to its higher Tc as drilling temperatures have increased with the increase in cutting speed. 


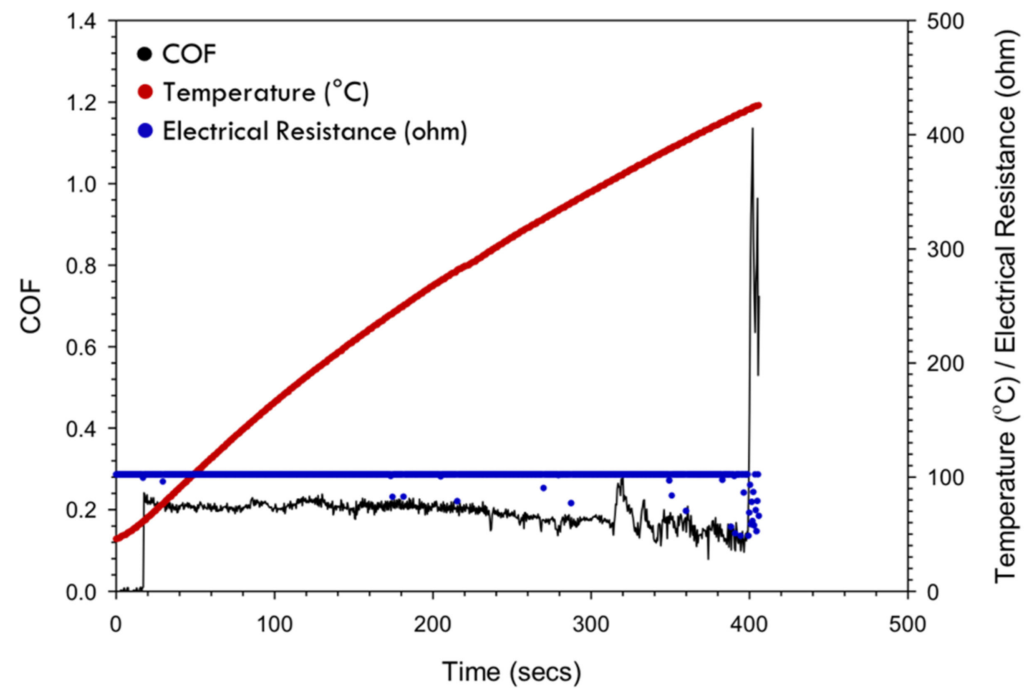

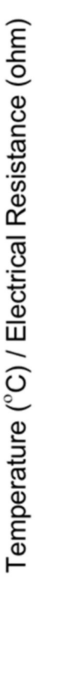

(a)

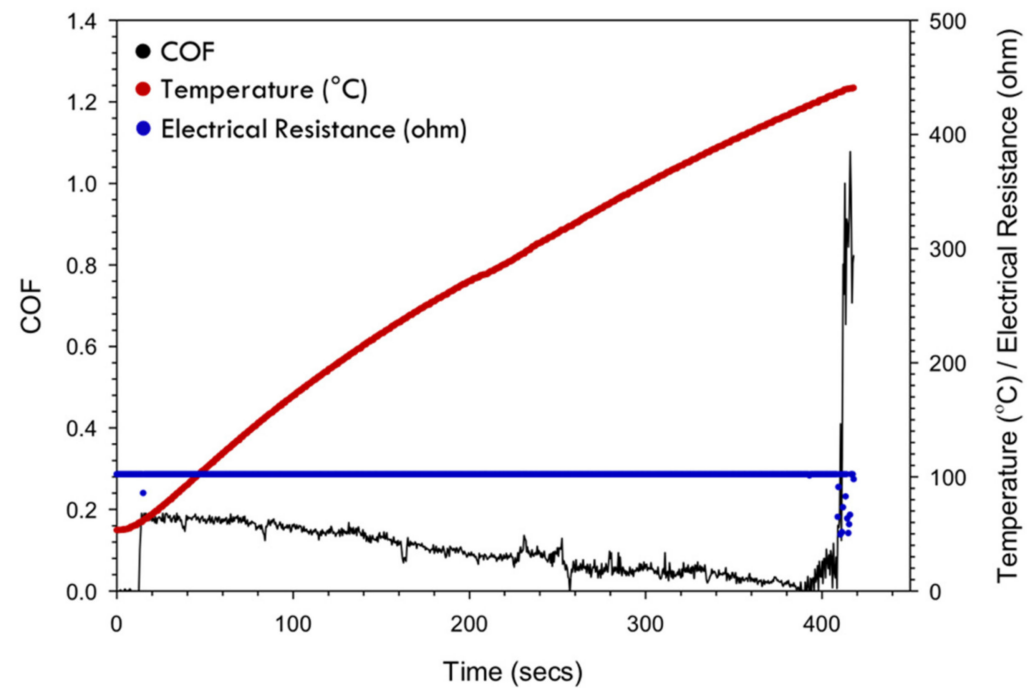

(b)

Figure 20. The COF, temperature, and electrical resistance variation against time plot for ball-on-disc tests with an Al-Mn alloy lubricated with neat oils of (a) the phosphorus-based additive and (b) the polymer-based additive under $3 \mathrm{~N}$.

The lubrication failure temperatures for each cutting fluid additive highlight that should these temperatures be experienced during drilling, failure might occur as a result due to BUE build-up on the drill bit, similar to the aluminum build-up on the steel surface. Typically, as the depth of the holes increase and temperatures rise, should the drilling temperatures exceed the lubrication failure temperature, failure could likely occur, and the drill bit would be stuck in the hole. Meanwhile, while the cutting fluids provide cooling to the drill bit, drilling temperatures are known to increase with the number of holes. If there is insufficient time between holes for drill temperatures to drop below the lubrication failure temperature, the drill bit might fail at the next hole. The tests also highlight the tribological behavior of the cutting fluid additives during the drill operation. These tests revealed a reduction in COF as temperatures approached $200{ }^{\circ} \mathrm{C}$ for the phosphorus-based additive which also displayed a considerably lower COF than the polymer-based additive from $200{ }^{\circ} \mathrm{C}$ till failure at Tc (Figure $2 \mathrm{~b}$ ). A COF reduction was not observed as distinctly for the polymer-based additive, although a slight reduction in COF was observed at elevated temperatures. Figure 3 confirms that, at a constant temperature of $200^{\circ} \mathrm{C}$, the phosphorus- 
based additive also showed lower COF values than the polymer-based additive under both $3 \mathrm{~N}$ and $5 \mathrm{~N}$. However, comparable COF values for both additives were observed at $100^{\circ} \mathrm{C}$, while higher $\mathrm{COF}$ values were observed for the phosphorus-based additives at $300^{\circ} \mathrm{C}$, which is above the Tc of this additive. This highlights the influence of temperature on the phosphorus-based additive, as this additive is more effective at an elevated temperature of about $20{ }^{\circ} \mathrm{C}$ for the $\mathrm{Al}$ alloys. Thus, provided that the cutting fluid can keep the drill temperatures within the temperature range where the phosphorus-based additive offers a lower $\mathrm{COF}$, and before it experiences lubrication failure, lower torque values might be experienced due to the lower $\mathrm{COF}$ within that temperature range.

Thus, during drilling, the phosphorus-based additive improved its performance within a certain temperature range prior to Tc. However, the polymer-based additive is less influenced by the temperature increase. A comparison of the electrical resistance (Figure 2) indicates that the polymer-based additive appeared to better hinder metalto-metal contact until failure than the phosphorus-based additive, which appeared to experience metal-to-metal contact at lower temperatures. However, after failure, the sliding track induced with phosphorus-based additive (Figure 9b) possessed severe damage on less than half the sliding track width, while the full sliding track width induced from the polymer-based additive (Figure 9a) was covered in severe damage. The surface damage on the sliding tracks corresponded with the aluminum adhesion observed on the steel counterface (Figure 18). It appears that the early metal-to-metal contact during tests with the phosphorus-based additive led to an initial thin layer of aluminum transferred to the steel surface, which was oxidized during the test aiding in COF reduction. The carbon-rich tribolayer on the Al-Mn surface sliding against the oxidized aluminum adhesion on the steel surface results in the initial COF observed during the test. At elevated temperatures, phosphorus was introduced into the carbon-rich tribolayer, which further aided in COF reduction, leading to the drop observed in the COF graph and was able to prevent higher aluminum build-up at failure and severe damage covering the sliding track on the AlMn surface. Phosphorus was observed on the aluminum sliding track after lubrication failure tests (Figure 13b) and overlapping oxygen and carbon at only $200{ }^{\circ} \mathrm{C}$ (Figure $12 \mathrm{~b}$ ) during tests at constant temperature for the phosphorus-based additive. The oxidized aluminum transfer on the steel surface due to early metal-to-metal contact in addition to the development of the phosphorus-rich tribolayer during temperature increase would explain the much lower COF observed during the lubrication failure tests in comparison to the constant temperature test at $200^{\circ} \mathrm{C}$. Thus, the formation of the phosphorus/carbon-rich tribolayer within the sliding track on the Al-Mn surface influenced the performance of the phosphorus-based additive. This tribolayer would have been formed during sliding contact at lower temperatures of around $200{ }^{\circ} \mathrm{C}$ and could limit metal-to-metal contact until failure occurred at the critical temperature. Thus, during the drilling procedure, once the tribolayer is formed from the phosphorus-based additive, it would be effective at reducing torque, as well as adhesion and damage to the tool surface until the critical temperature of above $280^{\circ} \mathrm{C}$. The performance of the phosphorus-based additive would thus depend on the phosphorus introduction into the carbon-rich tribolayer. The polymer-based additive forms a carbon-rich tribolayer on the Al surface which can sustain drilling to higher critical temperatures. However, the carbon-based tribolayer would be expected to result in higher torque values in the drilling procedure, while the tribolayer could be sustained till high drilling temperature. It can be argued that the behavior of the cutting fluids is responsible for the COF trend observed. The initial COF as temperatures initially increases is a result of the effect of the oil-in-water fluid, and the drop in COF as temperatures exceed $200{ }^{\circ} \mathrm{C}$ is the result of the increase in the release of oil due to the evaporation of water. However, tests show that the release of oil from the oil-in-water cutting fluid begins below $125^{\circ} \mathrm{C}$ for both cutting fluid additives with little disparity in the temperature difference. The reduction in COF was observed at much higher temperatures for the polymer-based additives than the phosphorus-based additive. Similar lubrication failure tests with the neat oils of cutting fluid additives (Figure 20) revealed similar behavior to that of the oil-in-water fluids 
(Figure 2). The neat phosphorus-based additive oil (Figure 20b) displayed a reduction in COF from $0.178 \pm 0.025$ to $0.095 \pm 0.013$ around $200^{\circ} \mathrm{C}$, just slightly higher temperatures than the oil-in-water fluid. Although another COF reduction to $0.059 \pm 0.012$ was observed at around $338^{\circ} \mathrm{C}$, the $\mathrm{COF}$ behavior of the neat oil and oil-in-water fluid were comparable despite the neat oil having higher critical temperatures. The polymer-based additive neat oil (Figure 20a) also displayed a reduction in COF from $0.192 \pm 0.011$ to $0.128 \pm 0.030$ at around $412{ }^{\circ} \mathrm{C}$. In addition, although the phosphorus on the aluminum surface at $200{ }^{\circ} \mathrm{C}$ (Figure 12b) overlapped with carbon, it did not correlate with every carbon occurrence on the aluminum surface, nor was it observed within carbon-rich locations at $100{ }^{\circ} \mathrm{C}$ (Figure 12a), and as such could not simply be associated with the residue from the release of the oil at elevated temperatures. Therefore, the behavior observed with this ball-on-disc test was more likely due to the additives' tribological behavior, as the tribological behavior of the neat oils was similar to that of the oil-in-water fluids.

The COF reduction of cutting fluid additives is correlated with the surface damage induced on the Al-Mn surface. However, at $200{ }^{\circ} \mathrm{C}$, lower surface damage and sliding track width corresponded with the lower COF value for the phosphorus-based additive under $3 \mathrm{~N}$. The EDS maps of the Al-Mn surface (Figures 11 and 12) also showed a better correlation with the COF trend. The low COF and surface damage on the Al-Mn surface could be related to the distribution of the carbon within the sliding tracks. At $200{ }^{\circ} \mathrm{C}$, the maps displayed overlaps in the oxygen and carbon within the sliding track indicating the formation of a carbon-rich tribolayer on the Al-Mn surface for both cutting fluid additives. A similar overlap of oxygen and carbon was observed on the Al-Mn surface at $100{ }^{\circ} \mathrm{C}$ (Figure 16a), however, the carbon concentration was less at this temperature. This formation of the tribolayer could be related to the COF values as lower COF was observed when a higher portion of the sliding track was covered with the carbon or when a higher carbon concentration was observed. Therefore, the low COF was related to the formation of the carbon-rich tribolayer. There was also less damage observed on the Al-Mn surface. This correlation was also observed with the lower COF for the phosphorus-based additive at $200^{\circ} \mathrm{C}$, where the highest area coverage and concentration of the carbon-rich tribolayer within the sliding track were noted. A high phosphorus concentration was also noted overlapping with the carbon at $200{ }^{\circ} \mathrm{C}$ on the Al-Mn surface. The formation of a phosphorus-rich boundary layer on the Al-Mn surface during the sliding at $200{ }^{\circ} \mathrm{C}$ would aid in reducing the COF. Previous studies have reported that the phosphorus additives act as anti-wear additives and are able to form phosphorus-rich tribo-chemical layer during machining [23]. Moreover, phosphorus additives are influenced by the tribological contact conditions; at relatively higher loads and temperatures, EP additives are expected to be activated and form the boundary layers [24,25]. This boundary layer can aid in relieving the metal-to-metal contact between the Al-Mn surface and the steel ball surface, acting like sacrificial films, reducing the friction and the damage on the contact surfaces [26]. The tribolayer formed with this additive was able to prevent damage to the Al-Mn surface and reduce aluminum adhesion to the steel surface. However, the carbon tribolayer formed by the polymer-based additive resulted in abrasive wear on the Al-Mn surface, likely due to its lower surface area coverage. Thus, the carbon tribolayer formed at lower temperatures and developed during temperature increase would likely be better adept at hindering metal-to-metal contact than that formed at a constant temperature. At $300{ }^{\circ} \mathrm{C}$, failure occurred for both cutting fluid additives. However, the lower COF for the polymer-based additive could be related to the higher Tc of the additive and the higher surface coverage of the carbon-rich tribolayer still observed on the Al-Mn surface.

An examination of the sliding tracks induced on the Al-Mn sample (Figure 8) showed lower sliding track width for the phosphorus-based additive than the polymer-based additive under both $3 \mathrm{~N}$ and $5 \mathrm{~N}$ from $100{ }^{\circ} \mathrm{C}$ to $300{ }^{\circ} \mathrm{C}$, demonstrating the better load-bearing capacity of the phosphorus-based additive. The distinct difference in sliding track width under $3 \mathrm{~N}$ confirms the significant improvement in lubricity obtained from the phosphorusbased additive at $200{ }^{\circ} \mathrm{C}$. However, this improvement at $200{ }^{\circ} \mathrm{C}$ was not sustainable as 
shorter sliding distances were observed under $3 \mathrm{~N}$ and $5 \mathrm{~N}$. The difference in the sliding track widths and the COF between the two additives was reduced as the load increased from $3 \mathrm{~N}$ to $5 \mathrm{~N}$. The difference in tribological behavior of the two additives at this temperature might not be as distinct as the load increases. Therefore, the tribological behavior of the phosphorus-based additive was dependent on temperature for the formation of the phosphorus/carbon tribolayer. This additive, however, possessed a lower Tc than the polymer-based additive. Nevertheless, the polymer-based additive tribological behavior did not depend as much on the temperature for the formation of its carbon tribolayer.

\section{Conclusions}

This study was performed to evaluate the tribological behavior of polymer-based and phosphorus-based cutting fluid additives on Al-Mn alloy during sliding contact with a steel ball. A series of ball-on-disc tests were performed to evaluate their behavior at $100{ }^{\circ} \mathrm{C}$, $200{ }^{\circ} \mathrm{C}$, and $300{ }^{\circ} \mathrm{C}$ under loads of $3 \mathrm{~N}$ and $5 \mathrm{~N}$, as well as to determine the temperature at which lubrication failure occurred $(\mathrm{Tc})$ at $3 \mathrm{~N}$. The results indicate:

1. The performance of the cutting fluid additives was influenced by the temperature, with the polymer-based additive possessing the higher lubrication failure temperature. The polymer-based additive displayed the more stable tribological behavior with a constant COF as temperature increased, with only a slight COF reduction at elevated temperatures. The phosphorus-based additive was more sensitive to increasing temperatures, with a considerable drop in COF occurring at $200^{\circ} \mathrm{C}$ until lubrication failure occurred at $283^{\circ} \mathrm{C}$.

2. The tribological behavior of the cutting fluid additives could be attributed to the formation of the tribolayer. The formation of a carbon-rich tribolayer occurred early during sliding at lower temperatures for the polymer-based additive, which remained stable until lubrication failure at elevated temperatures. The formation of a carbonrich tribolayer occurred at lower temperatures for the phosphorus-based additive. However, at $200{ }^{\circ} \mathrm{C}$, phosphorus was introduced into the tribolayer, which remained stable until lubrication failure. Therefore, the composition of the tribolayer depended on the temperature and the additive employed.

3. The tribological behavior of the phosphorus-based additive depended on the introduction of the phosphorus into the carbon-rich tribolayer, which occurred at around $200{ }^{\circ} \mathrm{C}$, and initiated improved mitigation of metal-to-metal contact during sliding.

Author Contributions: Conceptualization, J.M. and O.A.G.; methodology J.M. and O.A.G.; experiments, J.M. and O.A.G.; formal analysis, J.M., O.A.G. and R.A.R.; data curation, J.M., O.A.G. and R.A.R.; writing —original draft preparation, J.M.; writing—review and editing, O.A.G. and R.A.R. All authors have read and agreed to the published version of the manuscript.

Funding: Natural Sciences and Engineering Research Council of Canada (NSERC).

Institutional Review Board Statement: Not applicable.

Informed Consent Statement: Not applicable.

Data Availability Statement: Not applicable.

Acknowledgments: Financial support for this research was provided by the Natural Sciences and Engineering Research Council of Canada (NSERC) and Quaker Houghton. The authors would like to gratefully acknowledge Yixing Zhao, Yan Zhou, Kris Januszkiewicz, and Robert Evans of Quaker Houghton $(\mathrm{QH})$ for their valuable comments.

Conflicts of Interest: The authors declare no conflict of interest.

\section{References}

1. Duan, Z.; Li, C.; Ding, W.; Zhang, Y.; Yang, M.; Gao, T.; Cao, H.; Xu, X.; Wang, D.; Mao, C. Milling force model for aviation aluminum alloy: Academic insight and perspective analysis. Chin. J. Mech. Eng. 2021, 34, 1-35. [CrossRef]

2. Santos, M.C.; Machado, A.R.; Sales, W.F.; Barrozo, M.A.; Ezugwu, E.O. Machining of aluminum alloys: A review. Int. J. Adv. Manuf. Technol. 2016, 86, 3067-3080. [CrossRef] 
3. Januszkiewicz, K.; Riahi, A.; Barakat, S. High temperature tribological behaviour of lubricating emulsions. Wear 2004, 256, 1050-1061. [CrossRef]

4. Kelly, J.; Cotterell, M. Minimal lubrication machining of aluminium alloys. J. Mater. Process. Technol. 2002, 120, 327-334. [CrossRef]

5. Sreejith, P. Machining of 6061 aluminium alloy with MQL, dry and flooded lubricant conditions. Mater. Lett. 2008, 62, 276-278. [CrossRef]

6. Debnath, S.; Reddy, M.M.; Yi, Q.S. Environmental friendly cutting fluids and cooling techniques in machining: A review. J. Clean. Prod. 2014, 83, 33-47. [CrossRef]

7. Winter, M.; Bock, R.; Herrmann, C. Investigation of a new ecologically benign metalworking fluid in abrasive machining processes to substitute mineral oil based fluids. Procedia CIRP 2012, 1, 393-398. [CrossRef]

8. Huang, B.; Changhe, L.; Zhang, Y.; Wenfeng, D.; Min, Y.; Yuying, Y.; Han, Z.; Xuefeng, X.; Dazhong, W.; Debnath, S. Advances in fabrication of ceramic corundum abrasives based on sol-gel process. Chin. J. Aeronaut. 2021, 34, 1-17. [CrossRef]

9. Ozcelik, B.; Kuram, E.; Cetin, M.H.; Demirbas, E. Experimental investigations of vegetable based cutting fluids with extreme pressure during turning of AISI 304L. Tribol. Int. 2011, 44, 1864-1871. [CrossRef]

10. Rico, E.F.; Minondo, I.; Cuervo, D.G. The effectiveness of PTFE nanoparticle powder as an EP additive to mineral base oils. Wear 2007, 262, 1399-1406. [CrossRef]

11. Kumar, B.S.; Padmanabhan, G.; Krishna, P.V. Performance assessment of vegetable oil based cutting fluids with extreme pressure additive in machining. J. Adv. Res. Mater. Sci 2016, 19, 1-13.

12. Marano, R.S.; Smolinski, J.M.; Manke, C.W., Jr.; Gulari, E.; Messick, R.L. Polymer additives as mist suppressants in metal cutting fluids. Tribol. Lubr. Technol. 1997, 53, 25.

13. Gao, T.; Li, C.; Yang, M.; Zhang, Y.; Jia, D.; Ding, W.; Debnath, S.; Yu, T.; Said, Z.; Wang, J. Mechanics analysis and predictive force models for the single-diamond grain grinding of carbon fiber reinforced polymers using CNT nano-lubricant. J. Mater. Process. Technol. 2021, 290, 116976. [CrossRef]

14. Winkeljann, B.; Leipold, P.M.A.; Lieleg, O. Macromolecular coatings enhance the tribological performance of polymer-based lubricants. Adv. Mater. Interfaces 2019, 6, 1900366. [CrossRef]

15. Alves, S.M.; Barros, B.S.; Trajano, M.F.; Ribeiro, K.S.B.; Moura, E. Tribological behavior of vegetable oil-based lubricants with nanoparticles of oxides in boundary lubrication conditions. Tribol. Int. 2013, 65, 28-36. [CrossRef]

16. Guo, J.; Peng, R.; Du, H.; Shen, Y.; Li, Y.; Li, J.; Dong, G. The application of nano-MoS2 quantum dots as liquid lubricant additive for tribological behavior improvement. Nanomaterials 2020, 10, 200. [CrossRef] [PubMed]

17. Wang, Q.; Hou, T.; Wang, W.; Zhang, G.; Gao, Y.; Wang, K. Tribological properties of black phosphorus nanosheets as oil-based lubricant additives for titanium alloy-steel contacts. R. Soc. Open Sci. 2020, 7, 200530. [CrossRef]

18. Ma, J.; Mohammadi, J.; Zhou, Y.; Larsh, J.; Januszkiewicz, K.; Evans, R.; Zhao, Y.; Gali, O.A.; Riahi, R.A. An investigation into cutting fluid additives performance during machining processing of Ti-6Al-4V. Int. J. Adv. Manuf. Technol. 2020, 112, 977-987. [CrossRef]

19. Ma, J.; Gali, O.; Riahi, A. The Tribological Behavior of As-Sprayed Graphene Oxide-Tungsten Disulfide Hybrid Coatings. Tribol. Trans. 2019, 62, 828-838. [CrossRef]

20. Gali, O.; Tamtam, R.; Riahi, A. The tribological evaluation of graphene oxide and tungsten disulfide spray coatings during elevated temperature sliding contact of aluminum-on-steel. Surf. Coat. Technol. 2019, 357, 604-618. [CrossRef]

21. Decrozant-Triquenaux, J.; Pelcastre, L.; Prakash, B.; Hardell, J. Influence of lubrication, tool steel composition, and topography on the high temperature tribological behaviour of aluminium. Friction 2021, 9, 155-168. [CrossRef]

22. Brizmer, V.; Matta, C.; Nedelcu, I.; Morales-Espejel, G. The influence of tribolayer formation on tribological performance of rolling/sliding contacts. Tribol. Lett. 2017, 65, 57. [CrossRef]

23. Mistry, K.; Morina, A.; Erdemir, A.; Neville, A. Tribological performance of EP lubricants with phosphorus-based additives. Tribol. Trans. 2013, 56, 645-651. [CrossRef]

24. Johnson, B.; Wu, H.; Desanker, M.; Pickens, D.; Chung, Y.-W.; Wang, Q.J. Direct formation of lubricious and wear-protective carbon films from phosphorus-and sulfur-free oil-soluble additives. Tribol. Lett. 2018, 66, 2. [CrossRef]

25. Loehlé, S.; Righi, M.C. Ab initio molecular dynamics simulation of tribochemical reactions involving phosphorus additives at sliding iron interfaces. Lubricants 2018, 6, 31. [CrossRef]

26. Martin, J.M. Tribochemistry of Antiwear (AW) Additives. In Encyclopedia of Tribology; Wang, Q.J., Chung, Y.-W., Eds.; Springer: Boston, MA, USA, 2013; pp. 3728-3732. 